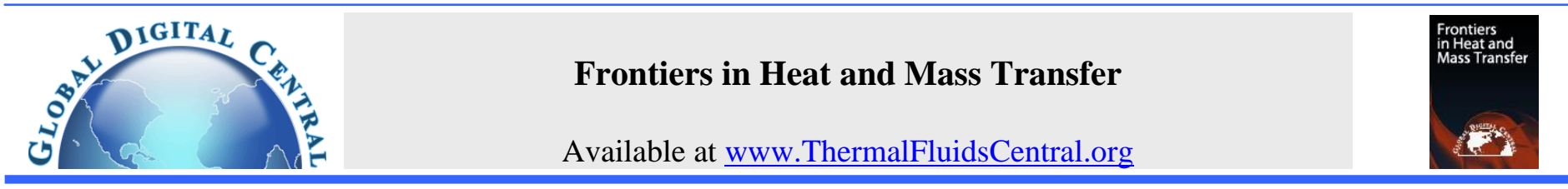

\title{
THERMAL BEHAVIOR OF LITHIUM-ION BATTERIES: AGING, HEAT GENERATION, THERMAL MANAGEMENT AND FAILURE
}

\author{
Daniela Galatro $^{\mathrm{a},{ }^{*}}$ Maan Al-Zareer ${ }^{\mathrm{a}}$, Carlos Da Silva ${ }^{\mathrm{a}}$, David A. Romero ${ }^{\mathrm{a}}$, Cristina H. Amon ${ }^{\mathrm{a}}$ \\ ${ }^{a}$ Department of Mechanical and Industrial Engineering, ATOMS Laboratory, University of Toronto, Toronto, Ontario, M5S 3G8, Canada
}

\begin{abstract}
This work presents a succinct review of the thermal behavior of lithium-ion batteries (LIBs) and its relationship with aging, heat generation, thermal management and thermal failure. This work focuses on the temperature effects that promote the main aging mechanisms in the anode and compare these effects among different cell chemistries for calendar and cycling aging modes. We review the strategies to mitigate aging, including the design of the battery thermal management system (BTMS), best practices of battery users to minimize the effect of stress factors, and the appropriate selection of the anode material. We discuss the heat generation and surface temperature variations in LIBs, including comparisons among different cell chemistries. We analyze the thermal failure of LIBs due to extreme events that cannot be countered by the BTMS, such as overcharge. Finally, the main challenges and opportunities related to the impact of the thermal behavior of LIBs on their performance and life cycle are identified, including trends in anode material selection, BTMS design, and fast-charging methods.
\end{abstract}

Keywords: lithium-ion batteries, aging, heat generation, thermal management, thermal failure

\section{INTRODUCTION}

A lithium-ion battery (LIB) is a rechargeable battery commonly used in electric vehicles (EVs) and portable electronics. It includes a positive electrode (cathode), a negative electrode (anode), and an electrolyte that acts as the conductor. The cathode is usually composed of metal oxide, and the anode of porous carbon. During a discharge process, as shown in Fig. 1, the $\mathrm{Li}^{+}$ions flow from the anode to the cathode through the electrolyte and separator. During a charging process, the direction of this flow is reversed from the cathode to the anode. The operation of the battery generates heat, which is mainly caused by resistive heating, or Joule heating, as the ions flow through the internal resistance of the battery during charge or discharge. Additional heat can also be generated during exothermic chemical reactions, or absorbed during endothermic reactions taking place in the cells.

During charge and discharge, a reversible intercalation reaction occurs, in which $\mathrm{Li}^{+}$ions enter and exit the electrodes' structure materials. The active materials of the electrodes and electrolyte participate in this reaction. Theoretically, the ions exchange process should work indefinitely, and the battery should always deliver $100 \%$ of its capacity. Nevertheless, degradation, referred to as 'aging' in the literature, is inevitable, decreasing the battery performance over time. This decrease in performance is usually measured in terms of the variation of capacity over time, a battery health indicator that strongly depends on the thermal behavior of the cell. This health indicator is usually used to determine the end-of-life (EOL) of an EV battery, which is considered to be reached when its capacity decreases to $80 \%$ of the nominal capacity at the beginning-of-life (BOL) (Galatro et al. 2020, Schimpe et al. 2018).

The thermal behavior of LIBs results from the combination of extrinsic stress factors such as the temperature, state-of-charge (SOC) and current load; and intrinsic characteristics of the battery cells. The temperature, in combination with SOC and current load, promotes degradation mechanisms that reduce the performance of LIBs. During the operation of mobility-driven applications such as EVs, aging occurs when charging or discharging the battery, hereafter referred to as 'cycling aging.' In EVs, the impact of the temperature on cycling aging must be mitigated by an embedded battery thermal management system (BTMS), which is designed to keep the temperature within a desired temperature range. The effectiveness of the BTMS is compromised as the battery ages due to the increased heat generation and the uneven aging degradation paths, a consequence of the cells' intrinsic heterogeneity. Safety concerns can also arise in case of cell failure due to events such as battery overcharge, triggering thermal runaway.

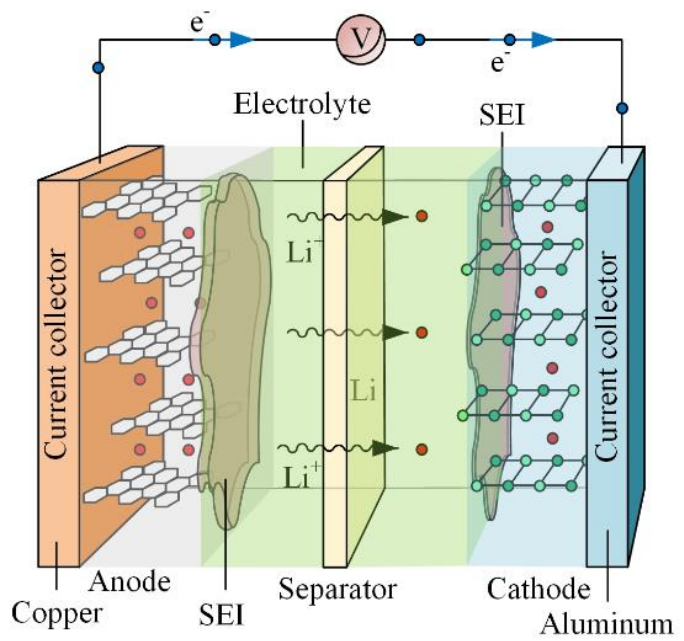

Fig. 1 Schematic of the $\mathrm{Li}^{+}$ions flow in a lithium-ion battery

* Corresponding author, e-mail: daniela.galatro@ mail.utoronto.ca 
Aging also occurs when the battery is at rest, hereafter referred to as 'calendar aging.' At rest, the battery is subjected to ambient temperatures without any temper strategy, which could result in more aggressive aging rates than those caused by cycling aging, depending on storage time and SOC. Furthermore, depending on the cell chemistry, different heat generation rates and temperature-dependent degradation paths are expected (Santhanagopalan et al. 2015).

This review paper presents a unique perspective of the thermal phenomena occurring at different temperatures domains in LIBs of different chemistries and their impact on battery performance, aging, and thermal failure. We discuss several strategies for mitigating this thermal impact beyond typical BTMS design considerations, including control strategies involving the battery management system (BMS), best user practices, and research advances on anode material. This paper also addresses the timely topic of battery fast-charging and its implication on heat generation, including current and emerging thermal management strategies to enable fast-charging.

This paper is organized as follows. Section 2 presents a comprehensive overview of aging in LIBs with a focus on the role of temperature as the main stress factor influencing aging. This section reviews the fundamental aspects related to (1) aging indicators, (2) aging during calendar and cycling modes, (3) degradation mechanisms in the anode, (4) degradation mechanisms in the cathode, (5) temperature domains affecting aging, (6) impact of cell chemistry on aging, (7) models that predict aging, (8) strategies to mitigate aging, and (9) aging and fast-charging. Section 3 addresses the role of aging on heat generation, temperature variations, and thermal modeling of LIB. Section 4 is dedicated to BTMSs. Section 5 describes the thermal behavior of LIBs associated with thermal runaway, including a comparison of this phenomenon among different cell chemistries. Section 6 summarizes the main challenges and opportunities related to the impact of the thermal behavior of LIBs on their performance and life cycle. Finally, Section 7 presents the concluding remarks.

\section{AGING IN LITHIUM-ION BATTERIES}

Aging refers to the degradation of a LIB over time, evidenced through battery performance-fade effects such as capacity and power fade, and internal resistance and impedance growth (Yang et al. 2018; Bandhauer et al. 2011; Wright et al. 2003; Waldmann et al. 2014; Guha and Patra 2018; Waag et al. 2013). Aging is caused by several physical and chemical mechanisms affecting the electrodes, electrolyte, separator, and current collectors (Birkl et al. 2017; Palacín 2018). Table 1 shows the levels involved in the cause and effect analysis of aging in LIBs (Birkl et al. 2017). This analysis includes three levels: causes, mechanisms, and effects. The effects can be quantified as chemical and performance effects.

Table 1: Levels involved in the cause and effect analysis of aging in LIBs (Birkl et al. 2017)

\begin{tabular}{|c|c|l|}
\hline \multicolumn{2}{|c|}{ Level } & \multicolumn{1}{c|}{ Description } \\
\hline 1 & Causes & $\begin{array}{l}\text { Stress factors such as time, temperature, SOC, } \\
\text { current load, stoichiometry, and mechanical stress }\end{array}$ \\
\hline 2 & Mechanisms & $\begin{array}{l}\text { SEI growth, SEI decomposition, electrolyte } \\
\text { decomposition, binder decomposition, graphite } \\
\text { exfoliation, structural disordering, lithium plating, } \\
\text { loss of electric contact, electrode particle cracking, } \\
\text { transition metal dissolution, and corrosion of } \\
\text { current collectors }\end{array}$ \\
\hline 3 & Effects & $\begin{array}{l}\text { Chemical: Loss of lithium inventory and loss of } \\
\text { active material }\end{array}$ \\
\cline { 2 - 2 } & $\begin{array}{l}\text { Performance: Capacity and power fade, resistance } \\
\text { and impedance increase }\end{array}$ \\
\hline
\end{tabular}

In the negative electrode or anode, aging is caused by the solid electrolyte interface (SEI) formation and growth, corrosion of the current collector, binder decomposition, and lithium plating (Agubra and Fergus 2013; Kindermann et al. 2017); while in the positive electrode or cathode, aging is caused by small volume changes during cycling, corrosion of the current collector, electrolyte decomposition, and dissolution of the active material in the electrolyte (Hausbrand et al. 2015). In the separator, aging causes a porosity decrease over time due to the SEI formation and growth (Kindermann et al. 2017). An appropriate porosity level in the separator is required to ensure sufficient ionic conductivity in the electrolyte (Kannan et al. 2018). An extensive review of the main mechanisms causing aging in LIBs is included in Section 2.3 of this paper.

The combined effects of stress factors, interactions between degradation mechanisms, and heterogeneities in the structure of the electrodes, pose enormous challenges for their modeling and diagnostics (Birkl et al. 2017). Due to the complexity of the aging phenomena, physics-based models are limited to including only the dominant mechanisms at the cell level, such as the formation and growth of the SEI and lithium plating (Birkl et al. 2017; Yang et al. 2017; Balagopal et al. 2018; Pinson and Bazant 2012; Tahmasbi et al. 2017).

\subsection{Aging indicators}

Capacity, power and internal resistance have been the preferred aging indicators of LIBs (Barré et al. 2013; Keil et al. 2016). The evolution of capacity and power over the lifetime of the battery is non-linear and may be separated into three regions, as shown in Fig. 2 (Santhanagopalan et al. 2015). These regions are (1) Region I or breakin region, which usually evidences a slight initial performance increase during cycling; (2) Region II or quasi-linear fade region; and (3) Region III or accelerating fade region.

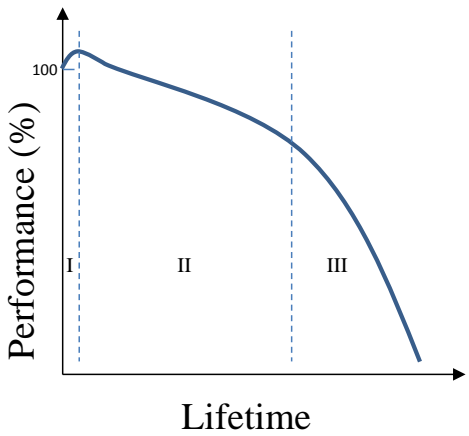

Fig. 2 Typical evolution of aging indicators during the battery lifetime expressed as relative performance (Santhanagopalan et al. 2015)

The break-in region (Region I) is affected by the manufacturing conditions of the cells. Thus, as shown in Figure 2, cells could experience a slight increase in capacity when they contain an excess of lithium that is released during the initial cycles of the cell. On the other hand, incomplete formation cycles at the manufacturing facility could cause a break-in process characterized by a sharp decrease in capacity during the initial cycles. Because of the uncertainty generated from these conditions, break-in processes in Region I pose challenges in identifying degradation paths during the first cycles of the cells. In Region II, the growth rate of degradation mechanisms, such as the SEI growth, exhibits a quasi-steady-state aging rate. In Regions I and II, it is imperative for the BTMS to maintain the operating temperature within a desired range to ensure the stability of the SEI layer. Lithium plating, another degradation mechanism, may also begin in these regions due to high charge rates. In the accelerating fade region (Region III), additional electrochemical processes can contribute to accelerating the existing degradation mechanisms. For instance, dissolved manganese in the electrolyte/anode interface might act as a catalyst for SEI growth (Santhanagopalan et al. 2015). In Region III, lithium plating outpaces degradation due to SEI growth, promoted by low-temperature charging. 


\subsection{Aging modes}

Aging occurs during both calendar mode, when the battery is at rest or stored, and cycling mode, when the battery undergoes cycles of charge and discharge during operation. In calendar mode, the LIB is usually exposed to the environmental conditions, and its temperature is not controlled; while in cycling aging, the operating temperature range of the LIB is controlled by the BTMS.

Calendar mode corresponds to the irreversible loss of capacity while the battery is stored (Keil et al. 2016). This effect can be accelerated or deaccelerated depending on the storage conditions, being the temperature the most significant stress factor, followed by the SOC. High temperatures $\left(>40{ }^{\circ} \mathrm{C}\right.$ ) contribute to lithium loss, resulting in less available lithium for intercalation and then inducing capacity fade. At the same time, low temperatures $\left(<10^{\circ} \mathrm{C}\right)$ contribute to loss of active material or less available active material for diffusion, modifying the battery chemistry (Barré et al. 2013).

The other stress factor contributing to aging during calendar mode is the SOC level. Cells stored at the same temperature but different SOCs age at different paces (Barré et al. 2013). Higher battery degradation effects are expected at high SOC levels, caused by a potential disequilibrium on the electrode/electrolyte interface, promoting secondary or side chemical reactions (Palacín 2018; Barré et al. 2013; Takada 2013). Accelerated aging tests during calendar mode have mostly explored the combination of temperature and SOC, measuring cell performance effects such as capacity fade, and impedance or resistance increase (Santhanagopalan et al. 2015). These tests reveal that aging is accelerated at high SOC and high temperature, and performance degradation effects are non-linear over time (Barré et al. 2013; Keil et al. 2016).

Cycling mode corresponds to the irreversible loss of capacity while the battery is being charged and discharged. Apart from the temperature and SOC, other stress factors become relevant during cycling, including the discharge or charge rate (C-rate) and the $\triangle \mathrm{SOC}$ (Galatro et al. $2020)$. The $\triangle S O C$ is the SOC variation during a cycle. As in calendar mode, high temperatures $\left(>40{ }^{\circ} \mathrm{C}\right)$ and high $\Delta$ SOCs $(>70 \%)$ promote degradation and SEI growth, resulting in battery power fade. This effect is worsened at high discharge or charge rates (Barré et al. 2013), and further accelerated with the combined effect of high temperatures, high C-rates and high $\triangle$ SOCs (Santhanagopalan et al. 2015).

\subsection{Aging mechanisms on the anode}

The SEI is formed on both electrode-electrolyte interfaces in the anode and cathode but is more prominent on the anode. The main stress factors promoting degradation on the anode are SOC, temperature, and overcharge (Barré et al. 2013; Liu et al. 2016). At high temperatures (> $50{ }^{\circ} \mathrm{C}$ ) and high SOC levels (> 80\%), the SEI may dissolve, and lithium salts -which are less permeable to the lithium ions- could be formed, creating resistance for the lithium ions to flow, and hence, increasing the anode impedance (Barré et al. 2013; Peled and Menkin 2017). At low temperatures $\left(<20^{\circ} \mathrm{C}\right)$, the diffusion of lithium within the SEI and graphite decreases, overlaying the electrode with lithium plating, inducing a faster degradation rate compared to the one at high temperatures (Pelen and Menkin 2017; Rauhala et al. 2018).

The anode in a LIB is usually composed of graphite (Qi et al. 2017). Graphite is a common carbon material which has high Coulombic efficiency and long-term cycle stability. The primary degradation mechanism on graphite electrodes is the formation and growth of the SEI (Pinson and Bazant 2012). This interface is a barrier formed during the first charge of a LIB, protecting the anode from corrosion and the electrolyte from reductions (An et al. 2016). The SEI is formed because of the instability of most electrolytes at the operating potential of the anode during charging. Over time, lithium is lost to the SEI layer, when it is combined with carbonates, fluorides and other radicals to mostly form inorganic salts. The SEI is permeable to the lithium ions and solvent present in the electrolyte. Also, the solvent interacts with the graphite and diffuses through the SEI, promoting graphite exfoliation, and generating small gas emissions mostly at high SOC levels (> 80\%), eventually cracking the SEI and inducing its expansion (Barré et al. 2013).

In addition to graphite, several carbon and non-carbon anode materials have been investigated as potential candidates for extending the lifetime of LIBs, including graphene (Luo et al. 2018), silicon (Wang et al. 2015; Parekh et al. 2019), sulfides (Shi et al. 2017), phosphides (Song et al. 2014), and transition metal oxides (Bhaskar et al. 2012). These materials promote a more stable electrochemical performance of LIBs at high temperatures, provide high energy density and improve the reversible capacity of LIBs. However, their commercialization has been limited due to their high cost compared to graphite (Luo et al. 2018).

Solid electrolyte interface (SEI). The electrolyte solution of LIBs is thermodynamically unstable at low/high potentials, compared to $\mathrm{Li} / \mathrm{Li}^{+}$. Therefore, right after the first charge of the cell, the electrolyte solution gains electrons on the graphite surface and forms the SEI. These reduction processes result in the deposition of organic and inorganic products on the graphite surface. This layer provides kinetic stability to further reductions in the electrolyte and prevents exfoliation of graphite due to solvent co-intercalation (Verma et al. 2010). The onset potential of the SEI formation has been widely adopted as $0.8 \mathrm{~V}$ (Verma et al. 2010; Edström et al. 2006), although this is not a fixed value. The thickness of the SEI layer varies from a few $\AA$ to tens or hundreds of $\AA$, being challenging to measure due to the partial solubility of some of its components in the electrolyte (Verma et al. 2010). The SEI layer influences the cell performance characteristics because Li-ions must pass through this layer (Narula, 2014). The growth or thickening of this passivating layer leads to higher internal resistance during the intercalation and de-intercalation of ions.

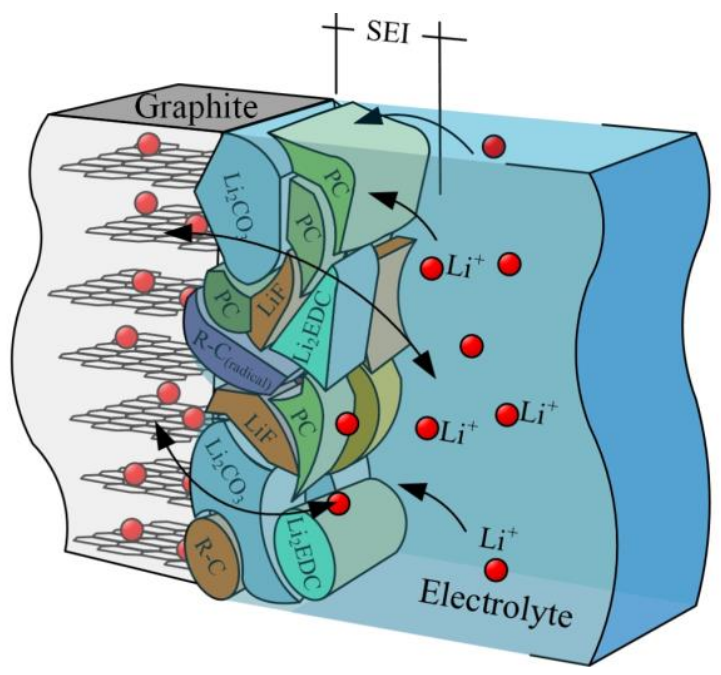

Fig. 3 Schematic of the solid electrolyte interface

Figure 3 shows the process of intercalation and de-intercalation of ions with a bidirectional arrow. The free movement of ions is affected by the SEI, which is a physical barrier located between the graphite and electrolyte. The SEI is seen as a dense layer of inorganic components followed by a porous organic layer next to the electrolyte phase (Verma et al. 2010; Bryngelsson et al. 2007; Edström et al. 2006). Several components are found in the SEI layer, such as polycarbonates (Aurbach 1996), alkyl-carbonates (Aurbach et al. 1997), lithium carbonates (Morigaki and Ohta 1998), represented in Fig. 3 as amorphous and amalgamated blocks.

The SEI composition and thickness vary during calendar and cycling modes. Also, the SEI can partially dissolve in a solvent of the 
electrolyte. The SEI layer is expected to be thinner at higher potentials and thicker at lower potentials (Bryngelsson et al. 2007). Nevertheless, the SEI changes are more prominent at elevated temperatures $\left(>80^{\circ} \mathrm{C}\right)$, much higher temperatures than those expected during normal cycling operation of a LIB $\left(15-45{ }^{\circ} \mathrm{C}\right)$. These changes are caused by the following reactions: (1) transformation or unstable carbonates and semi-carbonates to stable components such as $\mathrm{Li}_{2} \mathrm{CO}_{3}$, and (2) the reactions of the active material with the SEI, the SEI with the electrolyte, or the active material with the electrolyte (Narula 2014). Other exothermic reactions involving the SEI are expected at even higher temperatures $\left(>120{ }^{\circ} \mathrm{C}\right)$, contributing to the severe degradation of the battery performance and critically compromising its safety (Pasquier 1998).

The performance of the battery at high and low temperatures depends on the SEI stability and ability for passivation of the active material surface. Thus, during calendar mode, detrimental processes that cause self-discharge depend on the passivation effect of the SEI. During cycling mode, a stable SEI is required for cycling, mostly at high C-rate and $\triangle$ SOC (Narula 2014). Moreover, SEI can dissolve and/or evolve during cycling mode. Also, for both calendar and cycling modes, the SEI components are highly sensitive to the temperature. Therefore, BTMSs play a significant role in maintaining the temperature of LIBs within the desired range that assures the stability and passivation effect of the SEI.

Lithium plating. Characterized as lithium deposition on the anode in the form of dendrites, lithium plating is one of the major degradation mechanisms of LIBs, along with the SEI formation and growth. During lithium plating, the intercalation reaction of lithium-ions is limited by a partial reduction of these ions, forming metallic lithium at the anode (Harting et al. 2018) and creating an additional layer between the anode and the electrolyte. Lithium plating is mainly promoted by charging at high currents and low temperatures (Liu et al. 2016; Harting et al. 2018) and by overcharging. In Fig. 4, lithium plating is visualized as layers of deposited metallic lithium on the graphite, outside of the highresistance and lithium-depleted zones. Other anodes, such as those made of coke, hard carbons and lithium titanate, are less susceptible to this degradation mechanism (Agubra and Fergus 2013).

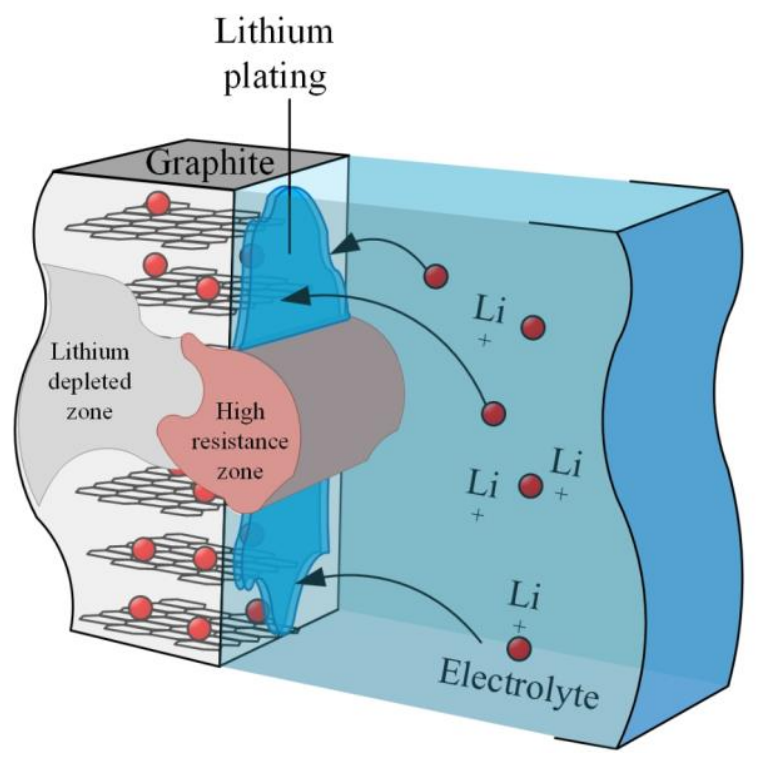

Fig. 4 Schematic of lithium plating

Lithium plating has a negative impact on the safety and performance of LIBs. Regarding safety, dendritic lithium is known for inducing internal short circuits and thermal runaway due to the exothermic reaction that occurs between the electrolyte and deposited lithium (Legrand et al. 2014). In terms of performance, lithium plating produces changes in the electrolyte polarization, reducing the performance of LIBs since it displaces the electrode potential from its equilibrium value.

\subsection{Aging mechanisms on the cathode}

The SEI layer is also formed on the positive electrode-electrolyte interface in the cathode; however, it is much thinner than that formed in the anode, and its effect is more difficult to quantify. The primary aging mechanisms of cathode materials and their effects are summarized in Table 2 (Lin et al. 2015). The main stress factors promoting degradation on the cathode are SOC and temperature (Barré et al. 2013). The aging mechanisms in the cathode depend on the cell chemistry and aging modes. In fact, the name of the cell chemistry is given by the material composition of the cathode. It is noteworthy that the material of the anode, graphite, is usually the same across all LIBs, except for lithium titanate oxide (LTO), which uses lithium-titanate nanocrystals instead of graphite in the anode. Developments in cathode materials could enhance the performance and lifecycle of LIBs. However, the development of novel anode materials with higher energy densities overrates the potential enhancement of cathode materials.

Low temperatures promote accelerated degradation on the following cell chemistries: lithium cobalt oxide (LCO), nickel manganese cobalt oxide (NMC), lithium nickel cobalt aluminum oxide (NCA), lithium manganese oxide (LMO), lithium iron phosphate (LFP), and LTO (lithium titanate oxide). On the other hand, the impact of high temperatures on aging is more significant in LCO cells, followed by NMC, NCA and LMO cells, and to a lesser extent, in LFP and LTO cells. A comparative analysis of the impact of cell chemistry on aging is included in Section 2.6.

Table 2: Aging mechanisms of cathode materials (Lin et al. 2015)

\begin{tabular}{|c|l|l|l|}
\hline \multicolumn{2}{|c|}{ Mechanism } & Effect on material & $\begin{array}{c}\text { Effect on } \\
\text { performance }\end{array}$ \\
\hline 1 & $\begin{array}{l}\text { Li+ } \\
\text { insertion/extraction }\end{array}$ & $\begin{array}{l}\text { Structural } \\
\text { disorder }\end{array}$ & Capacity fade \\
\hline 2 & Phase transition & $\begin{array}{l}\text { Crystal distortion } \\
\text { and mechanical } \\
\text { stress }\end{array}$ & Capacity fade \\
\hline 3 & Metal dissolution & $\begin{array}{l}\text { Loss of active } \\
\text { material and } \\
\text { surface layer } \\
\text { formation }\end{array}$ & Capacity fade \\
\hline 4 & $\begin{array}{l}\text { Electrolyte } \\
\text { decomposition }\end{array}$ & $\begin{array}{l}\text { Surface layer } \\
\text { formation }\end{array}$ & Impedance rise \\
\hline
\end{tabular}

\subsection{Aging and temperature domains}

The aging-kinetic behavior of LIBs allows defining three temperature domains associated with their performance: (1) low-temperature domain, approximately at temperatures lower than $20{ }^{\circ} \mathrm{C}$; (2) hightemperature domain, approximately at temperatures higher than $40{ }^{\circ} \mathrm{C}$ and less than the onset temperature promoting thermal runaway; and (3) intermediate domain, approximately at temperatures in between $20^{\circ} \mathrm{C}$ and $40{ }^{\circ} \mathrm{C}$, where aging is minimized. Therefore, better performance is expected in the intermediate domain, which offers a better tradeoff between battery performance and lifespan (Liu et al. 2016; Ye et al. 2016).

Lithium plating is the dominant aging mechanism in the lowtemperature domain. Aging effects induced by lithium plating include capacity loss and additional polarization. Capacity loss is caused by the loss of electronic connection between metallic lithium and the electrode particles during discharge. The dead lithium contained within the lithium plating layer accumulates on the electrode, causing loss of cyclable lithium (Bauer et al. 2015; Petzl et al. 2014). Additional 
polarization is caused by lithium deposited either at the graphite surface or the SEI layer. Lithium plating also consumes electrolyte species, decreasing its ionic conductivity and, therefore, leading to further polarization (Bauer et al. 2015).

During cycling at high temperatures, charge transfer and diffusion processes are faster. Hence, the rate of intercalation keeps its potential above the lithium plating potential. Therefore, the capacity loss at high temperatures is due to the loss of cyclable lithium caused by side reactions such as the reduction of electrolyte species and SEI formation and growth. This capacity loss is also due to the loss of active material in both electrodes, where less active material is available for the insertion of lithium due to blocking of active sites and particle cracking (Arora 1998; Christensen and Newman 2005). Also, high temperatures promote additional polarization caused by SEI growth, reduction of active material, and electrolyte dry-out (Bauer et al. 2015).

\subsection{Impact of cell chemistry on aging}

This section summarizes, compares and discusses the aging characteristics of different cell chemistries for calendar and cycling aging modes. Table 3 shows these aging characteristics by qualitatively comparing the impact of stress factors on aging for different cell chemistries and aging modes.

Table 3: Impact of stress factors on aging for different cell chemistries for both aging modes, where +++ denotes high impact, ++ denotes medium impact, and + denotes low impact.

\begin{tabular}{|l|c|c|c|c|c|c|}
\hline \multicolumn{2}{|c|}{ Stress factor } & \multicolumn{7}{|c|}{ Cell chemistry } \\
\cline { 2 - 8 } & $L C O$ & $N M C$ & $N C A$ & $L M O$ & $L F P$ & $L T O$ \\
\hline $\begin{array}{l}\text { High SOC / } \\
\Delta \text { SOC }\end{array}$ & +++ & +++ & ++ & ++ & ++ & + \\
\hline $\begin{array}{l}\text { Low SOC / } \\
\Delta \text { SOC }\end{array}$ & ++ & + & + & + & + & ++ \\
\hline $\begin{array}{l}\text { High } \\
\text { temperature }\end{array}$ & +++ & ++ & ++ & ++ & + & + \\
\hline $\begin{array}{l}\text { Low } \\
\text { temperature }\end{array}$ & +++ & +++ & +++ & +++ & +++ & n.a. \\
\hline High C-rates & +++ & ++ & + & n.a. & ++ & + \\
\hline
\end{tabular}

Calendar mode. Several researchers have studied aging during calendar mode for different cell chemistries (Keil et al. 2016; Ecker et al. 2012; Gismero et al. 2019). Keil et al. (2016) run several calendar aging tests with storage periods of nine and ten months on NCA, NMC and LFP 18650 lithium-ion batteries at $25^{\circ} \mathrm{C}, 40^{\circ} \mathrm{C}$ and $50{ }^{\circ} \mathrm{C}$, and for 16 different SOCs from 0 to $100 \%$. This study concluded that the capacity fade and resistance growth increased for these three battery chemistries at higher storage temperatures $\left(>40{ }^{\circ} \mathrm{C}\right)$. Nevertheless, in SOC intervals of more than $20-30 \%$, all the cell chemistries showed similar capacity fade rates, and a marked step in the capacity curve was observed at approximately $70 \%$ SOC for LFP cells and $60 \%$ for NCA and NMC cells. The capacity fade curves also showed that around 50\% of SOC, the capacity fade was more significant for the LFP and NMC cells, especially at higher storage temperatures $\left(40\right.$ and $\left.50{ }^{\circ} \mathrm{C}\right)$. On the other hand, at $50{ }^{\circ} \mathrm{C}$ and SOC above $70 \%$, NMC cells exhibited a higher capacity fade compared to NCA and LFP cells. This trend can also be observed in the results reported by Ecker et al. (2012), where 6 Ah NMC cells exhibited aggressive capacity fade at $65^{\circ} \mathrm{C}$ compared to lower temperatures $\left(35^{\circ} \mathrm{C}\right.$ and $\left.50^{\circ} \mathrm{C}\right)$ at the same SOC. All cell chemistries also showed a relatively flattening behavior of relative capacity after $70 \%$ SOC (Keil et al. 2016), except for NMC cells, whose relative capacity abruptly decreased when running above $95 \%$ SOC and high temperatures (Keil et al. 2016; Gismero et al. 2019; Ecker et al. 2012). Regarding resistance growth, the lowest increase was measured on LFP cells, showing no dependence on SOC. For NCA and NMC cells, the resistances increased at higher SOC values. For all chemistries, the authors also concluded that there was a direct correlation between capacity fade and resistance growth (Gismero et al. 2019).

Large LIB cells usually exhibit different responses in terms of performance and aging than smaller cells for the same cell chemistry, due to differences in current density, design and geometry, and spatial non-uniformity of the electrical potential (Kim et al. 2018). For instance, Kassem et al. (2012) and Grolleau et al. (2014) performed a set of calendar aging tests on $8 \mathrm{Ah}$ and $15 \mathrm{Ah}$ graphite/LFP cells, respectively, and at three different temperatures $\left(30^{\circ}, 40^{\circ} \mathrm{C}\right.$ and $\left.65^{\circ} \mathrm{C}\right)$, and three SOC levels (30\%, 65\% and $100 \%)$. These conditions promote loss of cyclable lithium, the primary source for the capacity fade, as identified by Kassem et al. (2012). Figure 5 shows the differences in relative capacity with respect to BOL as a function of time at $40^{\circ} \mathrm{C}$ and $65^{\circ} \mathrm{C}$. Values at $30^{\circ} \mathrm{C}$ were omitted in this comparison since they did not show significant differences in their trends at different SOC levels.

As shown in Fig. 5, the capacity fade sharply increases with storage temperature, and to a lesser extent, with SOC. The influence of SOC increases with temperature. Hence, the capacity fade increases as temperatures and SOC increase. However, the 15 Ah cells exhibited more aggressive aging than the $8 \mathrm{Ah}$ cells, since lower relative capacities were estimated at the same temperatures and SOCs for the same storage time. For instance, after 250 days at a storage temperature of $65{ }^{\circ} \mathrm{C}$ and $100 \%$ SOC, the relative capacity was 0.68 for the $8 \mathrm{Ah}$, compared to 0.55 for the $15 \mathrm{Ah}$. Also, the $15 \mathrm{Ah}$ cells showed a noticeable impact of higher SOC values on capacity fade $(65 \%$ and $100 \%$ SOC), compared to the 8 Ah cells.
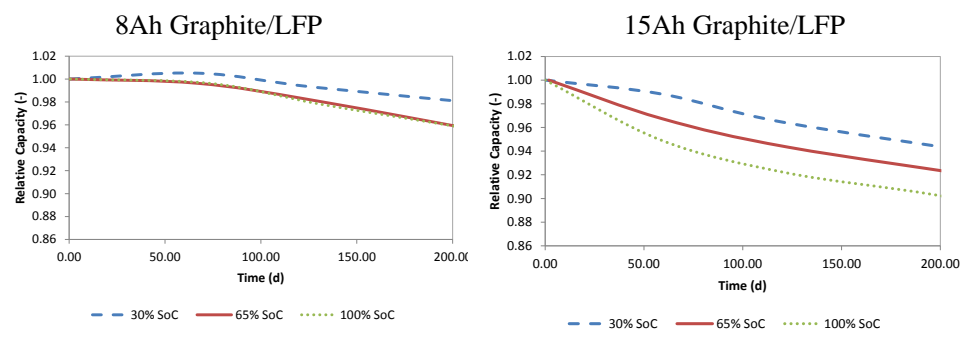

Temperature $=40{ }^{\circ} \mathrm{C}$

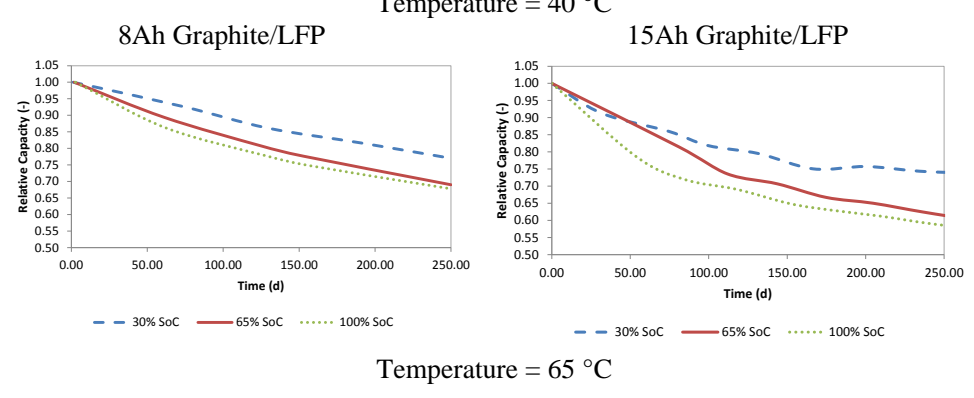

Fig. 5 Evolution of the relative capacity of LFP cells of 8 Ah and 15 Ah (Kassem et al. 2012; Grolleau et al. 2014)

Dubarry et al. (2018) conducted a literature review on calendar aging for different cell chemistries, including LTO, and graphite anode cells LFP, NCA, LCO, NMC, LMO, and composite blends NMC + LMO, and LCO + NMC. In their analysis, the authors concluded that capacity fade is influenced by both the temperature and SOC levels. Although a full comparison was not possible since the calendar aging tests in their literature review were performed at different temperatures and SOCs among their selected works, their main capacity fade findings are summarized as follows: (1) LCO cells experienced a very high degradation rate at high SOCs and temperature range of $40-50{ }^{\circ} \mathrm{C}$, with the degradation in these LCO cells being SOC-driven; (2) LFP cells had the lowest degradation rates when compared at the same temperatures and SOC conditions, with the degradation in these LFP cells being temperature-driven; (3) LCO cells were the most susceptible to degradation at high temperatures and SOCs; (4) the rest of graphite anode cells such as the composite blends, NMC, and NCA exhibited 
drastic degradation rates at high temperature $\left(50-60{ }^{\circ} \mathrm{C}\right)$, with NCA cells exhibiting a smaller change in degradation rates in the same temperature range; and (5) the influence of temperature and SOC was less significant in LTO cells, even showing low degradation rates at high temperatures, although they degraded faster at low SOCs.

Eddahech et al. (2015) performed calendar tests of four commercial LIBs of different cell chemistries at 1C-rate until the EOL criterion was reached. The battery cells included in their study were: (1) 12 Ah Kokam, graphite/NMC, prismatic; (2) 5.3 Ah LGChem, graphite/LMO-NMC, prismatic; (3) 7 Ah SAFT, NCA cylindrical; (4) LiFeBATT LFP $8 \mathrm{Ah}$, cylindrical. These batteries were stored at three different temperatures $\left(30{ }^{\circ} \mathrm{C}, 45^{\circ} \mathrm{C}\right.$ and $\left.60{ }^{\circ} \mathrm{C}\right)$ and three different SOC levels $(30 \%, 65 \%$, and $100 \%)$. The evolution of the capacity fade of these cells, as well as diagnostics revealed from Electrochemical Impedance Spectroscopy (EIS) tests, allowed the authors to conclude that LMO and NMC cells are very sensitive to high temperatures. They also observed dissolved manganese due to its reaction with the electrolyte. The consequence of this reaction is a high internal resistance increase with aging, which was confirmed through EIS tests. LFP cells showed the maximum calendar life, as well as excellent thermal stability. Finally, NCA cells were described as a compromise between high performance and long life cycles.

Calendar aging tests have also been performed in the lowtemperature domains. For instance, Jaguemont et al. (2016) conducted aging tests on $100 \mathrm{Ah}$ LFP cells at $-20{ }^{\circ} \mathrm{C}$ and $50 \%$ SOC. In their tests, the EOL criterion ( $80 \%$ of the nominal capacity) was reached in less than $415 \mathrm{~h}$ of storage time or 17 days, compared to $100-150$ days (Kassem et al. 2012; Grolleau et al. 2014) at a storage temperature of $65{ }^{\circ} \mathrm{C}$ and $65 \%$ SOC for the same cell chemistry. This aggressive aging behavior at very low temperatures poses a challenge in specific geographies such as Canada, where these temperatures are commonly expected in winter.

In calendar aging, we can conclude that the capacity fade sharply increases with storage temperature, while SOC has a lesser impact on aging for all chemistries. NMC, LCO and LMO cells are more agingsensitive than NCA and LFP cells in the high-temperature domain. Aggressive capacity fade is also expected in the low-temperature domain, as shown for LFP cells. LTO cells are less sensitive to high and low storage temperatures than NMC, LCO, LFP and NCA cells.

Cycling mode. A cycling aging study was conducted by Han et al. (2014) on five commercial LIBs: $20 \mathrm{Ah}$ LTO/NMC, $60 \mathrm{Ah}$ and $11 \mathrm{Ah}$ graphite/LFP, and $35 \mathrm{Ah}$ and $10 \mathrm{Ah}$ graphite/LMO. The batteries were charged at $1 / 3 \mathrm{C}$ and discharged at $1.5 \mathrm{C}$-rate, performed 90 cycles at 45 ${ }^{\circ} \mathrm{C}$, and 90 cycles at $5^{\circ} \mathrm{C}$, exposing the cells to high- and lowtemperature domains without the influence of the $\triangle \mathrm{SOC}$ and depth-ofdischarge (DOD). This sequence was repeated for 1000 cycles. The evolution of the capacity fade as a function of the number of cycles showed that the LTO/NMC cells experienced a negligible capacity fade after 1000 cycles. The aging diagnostics on the LFP and LMO cells revealed that both cells experienced a loss of lithium inventory and anode active material. LFP cells degraded to EOL of $80 \%$ at $200-300$ cycles, while LMO cells degraded at 420 cycles. The comparison between LFP and LMO cells is in agreement with other cycling trends showed in the literature (Dubarry et al. 2018), where LMO cells exhibit a longer life than LFP cells.

The influence of different DOD levels, C-rates and temperature on aging during cycling mode was studied by Wang et al. (2011). Their experimental setup included 2.2 Ah 26650 LFP cylindrical cells, including six different temperatures $\left(-30^{\circ} \mathrm{C}, 0^{\circ} \mathrm{C}, 15^{\circ} \mathrm{C}, 25^{\circ} \mathrm{C}, 45^{\circ} \mathrm{C}\right.$, and $\left.60^{\circ} \mathrm{C}\right)$, five levels of DOD $(10 \%, 20 \%, 50 \%, 80 \%$, and $90 \%)$, and four discharge rates $(\mathrm{C} / 2,2 \mathrm{C}, 6 \mathrm{C}$, and $10 \mathrm{C})$. This study showed, for instance, that EOL at $60{ }^{\circ} \mathrm{C}$ and discharge $\mathrm{C} / 2$ was reached at $140-150$ days for all DOD levels; therefore, the influence of this parameter is negligible. On the other hand, high C-rates contributed to increasing cell temperatures considerably, accelerating aging. The effect of the temperature is significant, revealing to be, along with C-rate, the most influential parameter on aging during cycling mode. Another example, EOL was reached at 754 cycles when cycling at $60{ }^{\circ} \mathrm{C}$, compared to 1707 cycles at $45^{\circ} \mathrm{C}$, for the same discharge rate of $\mathrm{C} / 2$.

$\mathrm{Wu}$ et al. (2017) performed cycling tests until reaching $20 \%$ capacity loss on $5 \mathrm{Ah}$ Kokam blend graphite/LCO-NCA cells at $10{ }^{\circ} \mathrm{C}$, $25^{\circ} \mathrm{C}$ and $40{ }^{\circ} \mathrm{C}$, and $1 \mathrm{C}, 3 \mathrm{C}$, and $5 \mathrm{C}$ discharge rates. In terms of the effect of the temperature, their results demonstrated that the mildest capacity loss was obtained at $25{ }^{\circ} \mathrm{C}$, while aggressive aging was observed at both $10{ }^{\circ} \mathrm{C}$ and $40{ }^{\circ} \mathrm{C}$. Two degradation paths were observed at $40{ }^{\circ} \mathrm{C}$; one cell showed linear capacity fade, while the other cell showed a non-linear trend on the capacity fade. This behavior was also observed in terms of the resistance evolution, one cell showing a continuous linear increase, and the other an accelerated increase. The effect of the discharge rate was analyzed at $25{ }^{\circ} \mathrm{C}$. In all cases, the capacity notably faded until approximately 300 cycles, from where the capacity loss experienced a quasi-linear behavior. The EOL was reached at 4800 and 3500 equivalent full cycles for 1C-rate and 5Crate, respectively.

Similarly, 40 Ah NMC cells were cycled at room temperature, $45^{\circ} \mathrm{C}$ and $65^{\circ} \mathrm{C}$, with full cycles at $1 \mathrm{C}$-rate (Jalkanen et al. 2015). The EOL was reached after 800 cycles at $45 / 65^{\circ} \mathrm{C}$, faster than that at room temperature. An increment in capacity, known as electrochemical milling (Jalkanen et al. 2015; Devie et al. 2014), was observed at the beginning of cycling, probably due to increased electrode active surface (refer to Region I in Fig. 2)

Devie et al. (2014) tested commercial-grade 13.4 Ah LTO/NMC cells, one through cycle aging process at $25{ }^{\circ} \mathrm{C}$, and other with an overcharge event after 125 cycles, both at a low C-rate. For the first cycling process, the capacity fade was on the order of $0.5 \%$ per 1000 cycles, and no impact in aging behavior was observed for the overcharge event.

Cycling aging tests have also been performed in low-temperature domains. For instance, Petzl et al. (2014) cycled cylindrical 266502.5 Ah graphite/LFP cells at low C-rates $(1 \mathrm{C}, \mathrm{C} / 2)$ and six temperatures $\left(-20^{\circ} \mathrm{C},-22^{\circ} \mathrm{C},-24^{\circ} \mathrm{C}\right.$, and $\left.-26^{\circ} \mathrm{C}\right)$. They quantified lithium plating by differential voltage analysis of the discharge profiles after charging at plating conditions, allowing quantifying the mass of deposited lithium, and proving that this degradation mechanism becomes more aggressive as the temperature decreases. Petzl et al. (2015) also run cycling tests at $-22{ }^{\circ} \mathrm{C}$ and $1 \mathrm{C}$-rate on the same type of cells. In their results, they observed that the capacity loss rate deaccelerates after 120 cycles, becoming almost constant near to EOL. This means that the lithium plating reduced after this inflection point. This effect was also observed in the results obtained by $\mathrm{Wu}$. et al. (2018), where $3.1 \mathrm{Ah}$ graphite/NCA cells were cycled at $-10{ }^{\circ} \mathrm{C}$ and three different $\mathrm{C}$-rates (1C, 2C, 3C). The capacity fade was more aggressive at higher $\mathrm{C}$-rates, but in all cases, an inflection point was observed, delimiting a first stage where the capacity fades aggressively, followed by a deaccelerating stage. Analogously, Tippmann et al. (2014) degraded NMC cells at 1C constant discharge rate and different temperatures $\left(<0 \quad{ }^{\circ} \mathrm{C}\right)$. They predicted lithium plating through the dropping of the anode potential as a measure of degradation, showing more aggressive potential dropping as the temperature decreases. The inflection point distinguishing the aggressive and deaccelerating stage was also observed at sub-zero temperatures for this chemistry.

Leng et al. (2015) investigated the effect of temperature on the aging rate for $1.35 \mathrm{Ah}$ graphite/LCO cells subjected to cycles at $1 \mathrm{C}$ rate and temperatures of $25{ }^{\circ} \mathrm{C}, 35{ }^{\circ} \mathrm{C}, 45^{\circ} \mathrm{C}$ and $55^{\circ} \mathrm{C}$. In their analysis, the authors concluded that increasing the operating temperature led to increasing the degradation rates of all processes occurring in the LIB, affecting the maximum charge storage capacity, charge transfer rate constant, and resistances of electrodes and electrode/electrolyte. For these cells, the capacity fade decreased quasilinearly, and after an inflection point, this decrement was accelerated and non-linear.

Overall, in cycling aging, high- and low-temperature domains contribute to accelerating aging when neglecting the effect of $\triangle \mathrm{SOC}$ 
and depth-of-discharge (DOD), in agreement with the aging behavior experienced in calendar mode. Temperature and C-rate are the most influential stress factor during cycling for all chemistries in the lowand high-temperature domain. The more suitable cell chemistries for applications requiring high C-rates are LTO and NCA, followed by LFP and NMC cells. During cycling, the BTMS plays a crucial role in maintaining the temperature within the desired range and minimizing the temperature variation among cells, and therefore, extending the lifetime of the battery. BTMSs should also overcome the increment of the uneven overheating of the cells as they age. Moreover, the demand for fast-charging poses an additional challenged related to the expected temperature rise due to high C-rates.

\subsection{Predicting Aging}

The state-of-health ( $\mathrm{SOH}$ ) of the battery is generally defined by the ratio between the nominal capacity at time $t$ and the initial capacity of the cell (Guha and Patra 2018). The SOH indicates the condition of the battery compared to its ideal beginning-of-life (BOL) condition. Initially, the battery $\mathrm{SOH}$ is $100 \%$ at the BOL; it increases a small amount (approximately 0.5\%) over the first cycles (Smith et al. 2017), and then decreases over time, as shown in Fig 2. The SOH can be estimated by the BMS. The threshold below which an energy or power application considers a battery unsuitable is arbitrary. For example, in EVs, this EOL threshold is achieved at $80 \%$ of its nominal capacity. The SOH indicates the battery aging level but also guides battery use. Several modeling approaches have been used in the literature to predict aging and $\mathrm{SOH}$, including electrochemical models, equivalent circuit models, and correlations from accelerated data (Barré et al. 2013).

Electrochemical models use the Butler-Volmer equations and porous electrode theory (Doyle and Newman 1995; Newman and Tiedemann 1975) to estimate cell performance. The rise of the SEI layer and lithium plating are robustly modeled and related to the capacity fade. A common simplification of robust electrochemical models, such as the single-particle model (SPM), assumes that each electrode is a single spherical particle. For instance, Afshar et al. (2017), developed a dynamical low-order model with multiple variable solid-state diffusivity equations, increasing the accuracy of the SPM. The electrochemical models are accurate but complex to formulate and require the measurement and estimation of several electrochemical parameters to accurately describe the cell performance. For these reasons, they have not been extensively used for online estimation of battery aging. Atomistic approaches at the nanoscale have also been employed for predicting aging, including density functional theory (DFT), which has been used to describe the intercalation reaction, and molecular dynamics (MD), which has been used to examine the SEI evolution (Dalverny et al. 2011; Wagemaker et al. 2011).

Equivalent circuit models are based on identifying and relating battery parameters from direct measurements over time to aging phenomena. These parameters are obtained by fitting these online or offline measurements to a specific equivalent circuit model (ECM) composed of resistances, capacitances, and inductors. EIS is a technique that has been used to collect relevant information for fitting ECMs. The increment of the ohmic and polarization resistances over time is proportional to the SEI thickness growth (Birkl et al. 2017). These models require limited information from electrochemical parameters; however, they do require a significant and diverse amount of data. The online implementation of these models in the BMS has been enhanced by coupling them with machine learning methods; they have been successfully used for the identification of aging-related parameters (Eddahech et al. 2012).

Correlations of stress factors with capacity fade, or impedance raise, obtained from accelerated aging tests. The effectiveness of these methods in representing the aging phenomena depends on how extensive is the operational envelope of the considered data in considering ranges of stress factors that capture the relevant aging phenomena during calendar and cycling aging (Galatro et al. 2020). This can be achieved with accelerated test data, online performance data captured by the BMS, or a combination of both sources of data. These models are resource- and time-intensive, and they might lack a physical meaning when correlating stress factors and performance effects. Alternatively, statistical methods have been used to estimate capacity fade over time and remaining-useful-life (RUL), by fitting the corresponding aging data to Weibull (Rohr et al. 2017) or Gamma distributions (Wu et al. 2019; Lin et al. 2019). These methods, in combination with machine learning techniques, can be implemented online in BMSs, offering an advantage over electrochemical and ECMbased methods, since they are capable of quantifying uncertainties related to cell-to-cell variation and scalability from cell to module to battery-pack levels (Rohr et al. 2017).

\subsection{Mitigating aging}

This section reviews the strategies to mitigate aging, including (1) the design of the BTMS, (2) best practices of battery users to minimize the effect of stress factors, and (3) the appropriate selection of the anode material

BTMS design. The BTMS is part of the BMS and includes hardware and software. The goals of a BTMS are: (1) to keep the cells at a uniform temperature and within a desired operating range, improving their electrical performance and lifetime; and (2) to prevent thermal runaway. The sources of heat are mainly due to the heat generated by the cells and heat transferred from the surroundings. A BTMS is designed to meet at least three constraints: (1) size, (2) safety, and (3) cost requirements. A comprehensive thermal characterization of the cell, modules, and pack shall be carried out before designing a BTMS, since the heat generated by the cells depends on the SOC, temperature and charge/discharge profiles (Santhanagopalan et al. 2015). Also, the BTMS design shall consider the variation of the cell surface temperature and the intrinsic cell-to-cell variations, which also pose challenges for designing a BTMS to minimize aging and extend the battery lifetime.

Best user practices. We have previously discussed the impact of the stress factors on calendar and cycling aging. The main contributions to minimizing the impact of these factors come from the user. Hence, the combination of environmental conditions and cycling patterns define the longevity of LIBs. Some of the recommended actions for users to extend the lifetime of the LIBs are: (1) avoid having a fully charged battery at high temperatures; (2) avoid high DODs; (3) avoid leaving the battery at rest at very low temperatures for prolonged periods (Wikner, 2018).

Anode material. The research on material selection for LIB anodes is ongoing and crucial for the feasibility of EVs due to its impact on battery life. Most LIBs rely on graphite materials for anodes since it has a low cost and high overall cell voltage (Cao et al. 2000). Nevertheless, there are several differences among commercial graphites. These differences are characterized in terms of their crystallinity, grain morphology, particle size and surface chemistry (Mao et al. 2018). For instance, in the study conducted by Mao et al. (2018), the authors tested NMC811 cathodes with six natural and synthetic graphite anodes. The variations in cell performance at the same charge and discharge rates were correlated with the chemical and structural properties of these graphite samples. The main findings of their research were: (1) longer life is strongly dependent on stable graphite crystallite sizes; (2) more stable long-term cycling is observed in those graphites with lower surface area; and (3) the concentration of SEI in all tested anodes varies significantly. On the other hand, graphene and transition element oxidegraphene anodes such as metal sulfides enhance the performance of LIBs (Luo et al. 2018), exhibiting a significant decrease of the heat generation rate in the cells and a high rate of reversible capacity due to 
their crystalline structure, which has a very low volume change during cycling. Furthermore, some nanocomposites, such as cobalt oxide reduced graphene oxide have shown a stable electrochemical performance of the cell even at a high temperature of $100{ }^{\circ} \mathrm{C}$ (Mussa et al. 2019).

\subsection{Aging and fast-charging}

Range anxiety is one of the main reasons why consumers are hesitating to use EVs (Needell et al. 2016; Lutsey et al. 2015). To be fully competitive with internal combustion engine vehicles, EV drivers should be able to recharge their batteries quickly, anywhere, through fast-charging (FC). A comprehensive review of FC methods in LIBs was done by Tomaszewska et al. (2019). FC methods are limited by (1) the kinetics of the battery, which is described by the intercalationdeintercalation reaction and the side reactions rates associated to aging, such as SEI and lithium plating; and (2) current limit, related to the maximum overpotential that can be applied to the battery. FC causes high heat generation, therefore higher temperature gradients, and contributes to increasing cell heterogeneity (Park et al. 2014). These conditions are favorable for SEI growth. On the other hand, when applied at very low temperatures $\left(<-20{ }^{\circ} \mathrm{C}\right)$, FC causes a drastic capacity loss due to lithium plating. The implications on the thermal management of LIBs are evident: a cooling strategy is required when using FC, while lithium plating could be eliminated by increasing charging temperature using a preheating strategy in cold weather conditions.

\section{HEAT GENERATION AND TEMPERATURE VARIATION}

The previous section presented a comprehensive review of the aging characteristics of LIBs, addressing calendar and aging modes at lowand high-operating temperature domains. This section reviews the conditions promoting aging in LIBs that are directly related to the cell's thermal behavior, including (1) heat generation rates, (2) overheating, and (3) variation of cell surface temperature. The thermal characteristics of LIBs, along with extrinsic stress factors, exacerbate the effect of the ambient temperature on aging. This section describes the sources of heat generation and the influence of the stress factors on reversible and irreversible heating in LIBs, including comparisons among different cell chemistries. The approaches for quantifying and modeling heat generation are also summarized in this section.

\subsection{Heat generation}

Heat is generated in LIBs from three sources: (1) Joule heating or 'ohmic' heating, which reduces the ability of electrons to move; (2) heat generation from electrode reactions, due to a charge transfer occurring between the electrodes and the electrolyte; and (3) entropic heating, resulting from the change of the arrangement of atoms within the crystal structure of the electrodes, caused by the intercalation and deintercalation of Li-ions (Santhanagopalan et al. 2015; Bandhauer et al. 2011). Joule heating is an irreversible heating source, while intercalation and de-intercalation reactions at the electrode-electrolyte interface are reversible heat generation sources (Kantharaj and Marconnet 2019).

The amount of heat generated from Joule heating can be calculated as follows (Santhanagopalan et al. 2015),

$q=\sigma\left(\nabla \phi_{s}\right)^{2}$

where, $\sigma$ is the electronic conductivity, and $\nabla \phi$ is the voltage gradient for a given current density. The higher the voltage gradient, the greater the rate of heat generation (Santhanagopalan et al. 2015). High rates of charge and discharge contribute to Joule heating.

During the charge and discharge of the battery, part of the kinetic energy associated with the intercalation reaction is lost as heat. The heat generation rate from the intercalation reaction can be calculated as follows (Santhanagopalan et al. 2015),

$$
q=\sum a_{s} i \eta
$$

where, $\eta$ is the overpotential, which is the difference between a theoretical voltage and the actual voltage under battery operating conditions, and $a_{s} i$ is the area-scaled reaction rate. The higher the overpotential, the greater the heat generation.

The entropic heat generation is quantified by including a correction factor to the overpotential, considering the change in temperature,

$\eta=\eta_{r e f}-\left(\frac{\partial U}{\partial T}\right)_{\text {Tref }}\left(T-T_{r e f}\right)$

where, $U$ is the equilibrium value for the potential at the reference temperature. The entropic heat generation exclusively depends on the selection of the electrode materials.

Bernardi et al. (1985) derived the following expression for heat generation in LIBs, based on a thermodynamic energy balance on a cell:

$$
q=I(U-V)-I\left(T \frac{\partial U}{\partial T}\right)
$$

Eq. (4) has been frequently cited in the literature (Bandhauer et al. 2011). The first term is the heat generation due to cell polarization. The second term is the entropic heat, expressed as the potential derivative with respect to temperature. Mixing effects and phase change are neglected in this expression. The electrode potential in Eq. (4) is determined at the average composition. This assumption was challenged by Rao (1997) since it leads to significant errors when estimating heat generation. Instead, a local heat generation method and thermodynamic balance were proposed. The thermodynamic balance includes an expression with the average enthalpy potential with entropic heat effects across the section where the electrochemical reactions take place, while the local heat generation method includes all local thermal effects occurring inside the battery. Enthalpies of mixing were later added by Thomas and Newman (2003), using a Taylor-series expansion for the molar enthalpy of each species. In large battery formats, resistive heating due to the current movement in the cathode and anode metal current collectors is added to the electrochemical heat generation process from Eq. (4) (Bandhauer et al. 2011).

The stress factors that influence the reversible and irreversible heating are:

- Ambient temperature: Heat generation rates increase faster at lower ambient temperature and higher discharge rates since polarization losses are higher at lower temperatures, leading to higher irreversible heat generation (Santhanagopalan et al. 2015; Kantharaj and Marconnet 2019).

- SOC: Low SOC (<25\%) and high DOD (> 75\%) result in an increment of the heat generation rate, reflected in the entropic coefficient. Also, high discharge C-rates (> 2C) increase irreversible heat generation due to increased overpotential (Kantharaj and Marconnet 2019).

- Charge and discharge C-rate: Heat generation rates increase as charging and discharging rates increase. Ohmic heat generation dominates at high C-rates (> 1C), while reversible heat generation dominates at low C-rates $(<1 \mathrm{C})$ (Kantharaj and Marconnet, 2019).

- Electrode microstructure: It impacts the heat generation distribution within electrodes and the cell internal temperature distribution. Thus, lower electrode porosities lead to 
significant Joule heating rates in the electrolyte and more likelihood of hotspots near the electrode-separator interface (Santhanagopalan et al. 2015; Kantharaj and Marconnet 2019).

The heat generation rate of LIBs defines the design of lithium-ion cells. For instance, large-format cells have large transfer areas, contributing to dissipating ohmic heat; nevertheless, uneven distribution of the active material across the electrodes is expected in cells of large formats, resulting in uneven distribution of the heat generation rate (Santhanagopalan et al. 2015). This heterogeneity condition worsens at the module and pack levels.

Different cell chemistries, including LMO, LFP and LCO cells with a graphite anode, exhibit heat generation values in the same order of magnitude (Kantharaj and Marconnet 2019). Variable heat generation characteristics are observed in LFP and NMC cathodes, while NMC generates more heat compared to the other cell chemistries (Lin et al. 2017). In LMO, LFP and NMC cells, irreversible heat generation depends on capacity, while reversible heat generation plays a significant role in LCO cells (Lin et al. 2017).

\subsection{Average cell temperature and variation on cell surface temperature}

The effect of the stress factors on the heat generation rates of lithiumion cells is observed when measuring the cell temperature during aging tests. For instance, in their cycling aging study on 2.2 Ah 26650 LFP cells at different DOD levels and ambient temperatures, Wang et al. (2011) reported the average cell temperatures measured at the surface of the cells during cycling. Table 4 shows the differences between the average cell temperature and the ambient temperature at overheating conditions as a function of the DOD and discharge C-rate. This ambient-to-cell temperature difference is an indirect measurement of heat generation. As shown in Table 4, the overheating increases as the DOD and discharge C-rate increase. These differences are more noticeable in the low-temperature domain $\left(0{ }^{\circ} \mathrm{C}\right)$, compared to the intermediate- and high-temperature domains. Also, in the lowtemperature domain, these differences are negligible at high DODs (80 $\%$ and $90 \%$ ).

Table 4: Overheating during a cycling aging study on 2.2 Ah 26650 LFP cells (Wang et al. 2011)

\begin{tabular}{|c|c|c|c|c|c|c|}
\hline \multirow{2}{*}{$\begin{array}{c}\text { Discharge } \\
\text { C-rate }\end{array}$} & \multirow{2}{*}{$\begin{array}{c}\text { DOD } \\
(\boldsymbol{\%})\end{array}$} & \multicolumn{5}{|c|}{ Ambient Temperature $\left({ }^{\circ} \boldsymbol{C}\right)$} \\
\cline { 2 - 7 } & $\mathbf{0}$ & $\mathbf{1 5}$ & $\mathbf{2 5}$ & $\mathbf{4 5}$ & $\mathbf{6 0}$ \\
\hline \multirow{4}{*}{2} & 10 & 4.5 & - & 1.1 & - & - \\
\cline { 2 - 7 } & 50 & 6.9 & - & 1.3 & - & - \\
\cline { 2 - 7 } & 80 & 7.6 & - & 1.4 & - & - \\
\cline { 2 - 7 } & 90 & 7.8 & - & 1.4 & - & - \\
\hline \multirow{4}{*}{6} & 10 & 9.0 & 2.0 & 2.0 & 1.7 & - \\
\cline { 2 - 7 } & 50 & 13.3 & 3.0 & 2.5 & 2.0 & - \\
\cline { 2 - 7 } & 80 & 14.0 & 3.4 & 2.7 & 2.2 & - \\
\cline { 2 - 7 } & 90 & 13.9 & 3.6 & 2.8 & 2.2 & - \\
\hline \multirow{4}{*}{10} & 10 & 11.6 & 2.9 & 2.6 & 2.3 & 2.6 \\
\cline { 2 - 7 } & 50 & 17.5 & 4.0 & 3.3 & 2.8 & 2.7 \\
\cline { 2 - 7 } & 80 & 18.0 & 4.2 & 3.6 & 3.0 & 3.0 \\
\cline { 2 - 7 } & 90 & 17.9 & 4.3 & 3.7 & 3.2 & 3.2 \\
\hline
\end{tabular}

Madani et al. (2018) measured the surface temperature evolution of 13 Ah LTO cells cycled at three ambient temperatures $\left(30^{\circ} \mathrm{C}, 40^{\circ} \mathrm{C}\right.$, and $50{ }^{\circ} \mathrm{C}$ ), with discharge rates up to $8 \mathrm{C}$. In addition to cell temperature measurements, they employed an isothermal calorimeter to investigate the thermal behavior of the cells. They noticed that heat generation rates were similar at $40{ }^{\circ} \mathrm{C}$ and $50{ }^{\circ} \mathrm{C}$, while the maximum and minimum amount of heat generation was registered at $30{ }^{\circ} \mathrm{C}$ and 50 ${ }^{\circ} \mathrm{C}$, respectively.

In addition to the increment of the cell temperature compared to the ambient temperature as the stress factors become more aggressive, Rumpf et al. (2018) observed an intrinsic non-uniformity on the surface cell temperatures. Since the temperature plays a significant role in LIB aging, the non-uniformity of the temperature distribution may cause imbalanced degradation and cell performance. At the cell level, improvements can be made on manufacturing tolerances for homogenizing material and physical properties. At the pack level, improvements in the cooling and heating architectures can be included.

As an example of the variation of the cell's surface temperature, Goutam et al. (2015) performed a comparative study of the surface temperature distribution of three commercial LIB pouch cells of different chemistries using infrared (IR) thermography. In their work, $20 \mathrm{Ah}$ (NMC), $14 \mathrm{Ah}$ (LFP) and 5 Ah (LTO) cells were used, applying load profiles with micropulse at $80 \mathrm{~A}$ and $80 \%$ SOC. The IR images during these cycles at different times showed that the evolution of the surface temperature contour exhibits different patterns for all cells, even different hot-spot locations. The temporal and spatial distribution of the overheating contributes to the uneven and accelerated aging of the cell. This level of uncertainty and variability influences the estimation of the $\mathrm{SOH}$ when scaled-up from cell to module to pack levels. It also influences the BTMS design and the balancing strategy of the BMS. Furthermore, the inaccurate quantification of the $\mathrm{SOH}$ poses a challenge when designing energy storage applications for second-life, potentially affecting the sustainability of the LIB lifecycle.

\subsection{Modeling thermal behavior of LIBs}

In previous sections, we reviewed the sources of heat generation in LIBs, the influence of the stress factors on the reversible and irreversible heating, and the variation on the surface cell temperature and its impact on aging. As a consequence of the inextricable links between the electrochemical and thermal characteristics of LIBs, the thermal behavior of LIBs must be coupled with performance and aging models through electro-thermal models capable of predicting the temperature distribution in LIBs. The main thermal models of LIBs fall into two main categories: (1) lumped models and (2) spatial and spatialtemporal models that rigorously represent the battery cell, module and pack.

In a lumped thermal model, it is assumed that the temperatures do not spatially vary within a battery cell (Chen et al. 2017). The main thermal parameters required for these models are the thermal resistances, electric contact resistances, and heat capacities. These methods are useful for small cells. For large scale cells, the temperature prediction is poor with lumped models. On the other hand, spatial and spatial-temporal models predict the non-uniform temperature profile within cells, since they can predict spatial distribution and temporal variation of the Li+ concentration (Jiang and Peng 2016) as a function of the discharge rate, providing input to coupled models combining thermal and electrochemical effects (Chen et al. 2017; Yan et al. 2013; Jiang et al. 2013).

At the cell level, physics-based models predict the effect of varying the composition and structure of the cell and its different heat generation mechanisms (Bandhauer et al. 2011). These models predict temperature distribution within a cell, assuming negligible microscale effects, limiting its applicability to predicting localized hot spots (Wiedemann et al. 2013). 3D versions of these thermal-electrochemical models can also predict the effect of stress factors and electrochemical cell parameters on heat generation, such as DOD, discharge C-rates, current density and electrode thickness (Bandhauer et al. 2011).

The granular microstructure of electrodes plays a crucial role in understanding the interfaces at the particle scale and their correlation with effective transport properties. At the granular level, some thermal 
models can analyze the effect of grain morphology, porosity and current density distribution on entropic and Joule heating (Latz and Zausch 2015).

\section{BATTERY THERMAL MANAGEMENT SYSTEM}

The primary purpose of the BTMS is to maintain the battery temperature within an optimal operating range, usually between $25^{\circ} \mathrm{C}$ and $50^{\circ} \mathrm{C}$ (Al-Zareer et al. 2018). However, there is no consensus on this optimal temperature range. Pesaran (2001) suggested a temperature range between $25-40{ }^{\circ} \mathrm{C}$. Karimi and $\mathrm{Li}$ (2012) used available data for modeling in the range of $20-40{ }^{\circ} \mathrm{C}$ to keep a uniform voltage distribution within the pack. Furthermore, Wang et al. (2015) estimated the optimal temperature range for forced air cooling between $20-35$ ${ }^{\circ} \mathrm{C}$. Regardless the target temperature range, an effective BTMS must be capable of (i) maintaining all the cells in the pack within the desired temperature range, (ii) providing both cooling and heating depending on the ambient temperature, (iii) ensuring minimum intra- and inter-cell temperature variations in the pack, and (iv) providing safety mechanisms against thermal runaway. It is also imperative for the BTMS to be lightweight, easy to service, and economically feasible, which ultimately depends on how rigorously the thermal management strategy is used to mitigate battery aging, at the expense of vehicle range and efficiency. The rise of the EV industry and the increasing demand for highly efficient, high-energy-density and long-lasting batteries are creating novel engineering challenges in which temperature and aging effects are driving new research paths towards more advanced BTMS

There exist a large variety of BTMSs, whose characteristics have been extensively reviewed in the literature (Kim et al. 2019). Based on the phase of the cooling or heating medium (coolant), BTMSs are categorized as air-based (Karimi and Li 2012), liquid-based (Rao et al. 2017), solid-to-liquid phase change materials (PCMs) (Yan et al. 2016, Orr et al. 2019), and liquid-to-vapor boiling-based phase change systems (Al-Zareer et al. 2019). Alternatively, based on the response of the system to temperature variations in the battery, whether the response is triggered by a control system or a thermophysical characteristic of the coolant, BMTSs are categorized as active (Safdari et al. 2020) and passive (Fan et al. 2013).

The operating and storage temperature of a LIB significantly affects its lifespan. In other words, it directly affects the degradation rate, which changes as the battery ages and is more aggressive during second-life. Thus, the BTMS must adapt to the SOH of the cells and control the temperature to decelerate the degradation rate. Since the SOH could be measured online by the BMS at the battery pack level, the computational strategy conceived for this measurement shall consider the intrinsic cell-to-cell variation or 'spreading' that defines different degradation paths of the cells. Spreading is somehow tackled when balancing algorithms embedded in the BMS are employed to maximize the available capacity of the pack. Therefore, the temperature control strategy to minimize degradation rate requires adding a level of integration and complexity between the BTMS and BMS that could pose computational challenges and potentially, increasing the energy consumption of the BTMS.

Typically, BTMSs are not tuned for degradation effects. There is a limited number of works in the literature that address this coupled functionality, which represents a tremendous opportunity for further advances in this field. For instance, Neubauer and Wood (2014) implemented the NREL's Battery Lifetime Analysis and Simulation Tool for Vehicles (BLAST-V) to assess the performance of a LIB based on a set of factors that include the effects of the driver behavior, cabin thermal management, BTMS, and climate. BLAST-V is an EV simulator that predicts the long-term effects of various operating conditions of a LIB. The BLAST-V model uses the high-fidelity battery wear model, which includes electrical and thermal performance models, to account for the degradation of the batteries due to various design and operating conditions, including but not limited to the vehicle power train, battery control strategy, local climate, driving and charging patterns, battery chemistry, and battery performance. Similarly, Yuksel et al. (2017) integrated a degradation model into an air-based BTMS design to better estimate the battery size, capacity and configuration of a plug-in hybrid EV. By implementing the degradation model of Wang et al. (2011), Yuksel et al. (2017) were able to increase the battery life by a factor of 1.5-6.0 compared to not employing a BTMS, depending on the ambient temperature. Other degradation models, such as the temperature- and capacity-dependent dynamic response impedance model developed by Xia et al. (2019) show promising results and can be a potential candidate for integration with BTMSs.

\section{THERMAL FAILURE}

In the previous sections, we reviewed the causes and effects of aging on the performance of the thermal behavior of LIBs, both at rest and during cycling. In some LIB-driven applications such as EVs, embedded BTMSs regulate the temperature within the desired range to maximize the LIB lifetime, and minimize any potential safety-related issue promoted by high temperatures. In addition to the BTMS, safety features are also added in case of unmanageable extreme events, or simply, a failure of a cell. Nevertheless, these events can still occur in LIBs, despite including these thermal mitigation measures. The failure of a single cell can generate a large amount of heat, and this heat can trigger a thermal runaway of adjacent cells, causing the failure of the entire battery pack. Thermal runaway occurs when the cell temperature exceeds a critical temperature; the cell then emits gases produced from initial degradation reactions, followed by smoke, cell ignition, and combustion (Abada et al. 2016). The activation conditions leading to thermal runaway include (1) internal short circuit between metals (current collector foils), between electrodes, and between the current collector and anode; (2) mechanical abuse, and (3) overcharge abuse (Abada et al. 2016; Feng et al. 2019).

Thermal runaway is characterized by three temperatures (Feng et al. 2019)

- The onset temperature $\left(\mathbf{T}_{1}\right)$, when the self-heating becomes detectable. The mechanism for this heat source is associated with SEI decomposition.

- The trigger temperature $\left(\mathbf{T}_{2}\right)$, related to the thermal stability of the battery. This temperature is reached once the separator has collapsed or melted. This temperature dictates the usability of LIBs (Feng et al. 2014).

- The maximum temperature $\left(\mathbf{T}_{3}\right)$, the temperature that the battery can reach during thermal runaway. It is caused by oxidation and reduction reactions between the electrodes. This temperature is higher for cells with higher energy density. The difference between $T_{3}$ and $T_{2}$ is associated with the total heat released during a thermal runaway.

When performing calorimetric measurements, it is possible to identify three cell temperature regions as a function of the SOC and temperature: (1) non-self-heating, (2) self-heating, and (3) thermal runaway (Nguyen et al. 2019). The self-heating reactions occur when the SEI reacts with the active material or electrolyte, usually at a temperature above $120{ }^{\circ} \mathrm{C}$. The self-heating reactions are then accelerated by reactions occurring between the cathode and electrolyte. For instance, Mendoza-Hernandez et al. (2015) performed a set of accelerating rate calorimetry (ARC) measurements on 18650 cells (800 mAh LCO-graphite and $720 \mathrm{mAh}$ LMO-graphite). The corresponding thermal mapping of these cells is shown in Fig. 6.

As shown in Fig.6, the onset and thermal runaway temperatures of the LCO cells in the self-heating region depend on the SOC, dropping as the SOC increases; while in the LMO cells, it was possible to observe two and three self-heating regions and almost constant onset temperatures from a SOC of $25 \%$. 


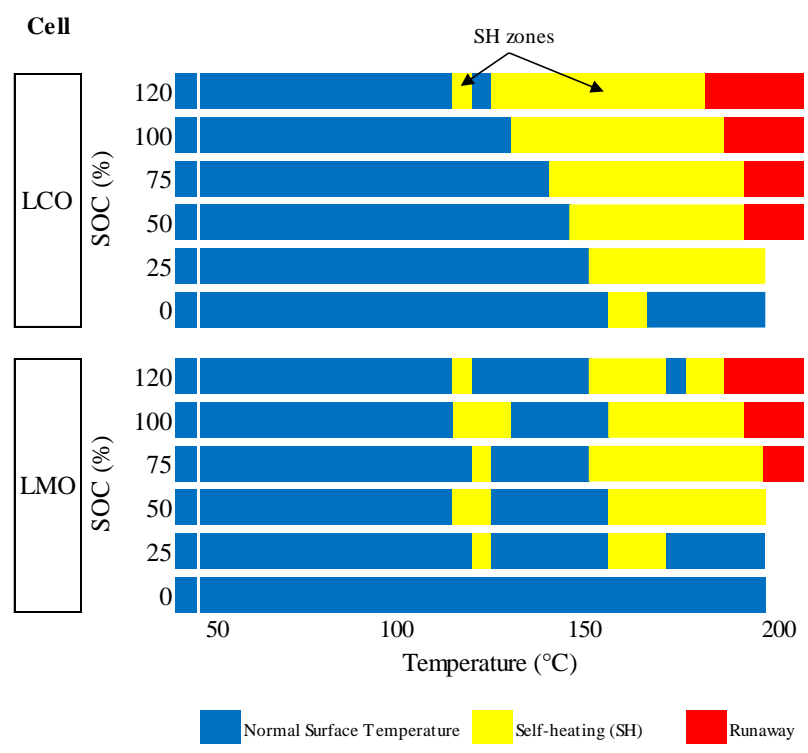

Fig. 6 Mapping of LCO and LMO cells at different SOC and temperatures (Mendoza-Hernandez et al. 2015)

Similarly, Golubkov et al. (2015) performed thermal runaway tests on 3.35 Ah NCA-graphite and 1.1 Ah LFP-graphite cells. They demonstrated that discharged cells showed no thermal runaway up to approximately $250{ }^{\circ} \mathrm{C}$, while charged cells showed a drastic thermal runaway behavior. The maximum temperatures were $1075{ }^{\circ} \mathrm{C}$ and 448 ${ }^{\circ} \mathrm{C}$ for the NCA and LFP cells, respectively, demonstrating that, for these cell chemistries, the severity of the thermal runaway increases with increasing SOC. Based on the drastic reduction of onset temperature for overcharged cells, the authors hypothesized that overcharge could cause metallic lithium deposition on the anode, compromising the thermal stability of the cells. Kvasha et al. (2018) investigated thermal runaway using ARC on 3.3 Ah NCA-Graphite, 1.1 Ah LFP-Graphite, and 16 Ah NCA-LTO cells, at 0, 50 and 100\% SOC. Their conclusions are aligned with those of previous works (Golubkov et al. 2015; Kvasha et al. 2018) in terms of the effect of the SOC on the severity of the thermal runaway. They concluded that the LFP cells are the safest cells due to the intrinsic thermal stability of this cathode. To improve thermal stability, they recommended the implementation of protective coatings on the cathodes.

Thermal runaway on other chemistries such as NMC was investigated by Liu et al. (2016) using copper slug battery calorimetry (CSBC), and compared against LCO and LFP cells. They concluded that LCO released the highest amount of heat $(37 \mathrm{~kJ} / \mathrm{cell}$ at $100 \%$ SOC), followed by NMC cells and LFP cells (34 and $14 \mathrm{~kJ} /$ cell, respectively). The typical onset temperatures among different electrodes are shown in Table 5. The LCO cell experiences the lowest onset temperature, significantly lower than those of other cell chemistries, while NCA and LMO exhibit the highest values. In terms of anodes, the difference between ordinary graphite and artificial is not significant.

The time sequence of the thermal runaway includes different stages for different cell chemistries. For instance, Zheng et al. (2018) used ARC and differential scanning calorimetry (DSC) and estimated that NMC cells exhibit four stages: Stage I, which starts from $100{ }^{\circ} \mathrm{C}$ and ends at $134.8^{\circ} \mathrm{C}$, right before the shrinkage of the separator. In this stage, the SEI decomposition and self-discharge of the cathode are the primary sources of heat generation. Stage II, from $134.8^{\circ} \mathrm{C}$ to $173.4{ }^{\circ} \mathrm{C}$, when a massive internal short circuit occurred. The leading cause of heat released in this stage is an internal short circuit. Stage III, from $173.4{ }^{\circ} \mathrm{C}$ to $247^{\circ} \mathrm{C}$, when thermal runaway is triggered. The main cause of heat released in this stage is the reaction of anode and cathode materials with the electrolyte. Stage IV, from $247{ }^{\circ} \mathrm{C}$ to $886.3{ }^{\circ} \mathrm{C}$, experiencing an exponential increase in the temperature rise. Similarly, LFP cells also develop thermal runaway in four stages, at different temperatures, compared to NMC cells. Nevertheless, LCO-LTO cells, only experienced two stages: Stage I, from $85^{\circ} \mathrm{C}$ to $190.6{ }^{\circ} \mathrm{C}$, led by an exothermic reaction in the anode, and heat released by an internal short circuit. Stage II, from $190.6{ }^{\circ} \mathrm{C}$ to $634.3{ }^{\circ} \mathrm{C}$, where the generation is caused by decomposition reaction of the cathode and anode materials with electrolyte.

Table 5: Comparison of onset temperatures of the electrodes inside the lithium-ion batteries (Mendoza-Hernández et al. 2015; Golubkov et al. 2015; Kvasha et al. 2018)

\begin{tabular}{|l|c|c|}
\hline Electrode & Chemistry & Onset Temperature, ${ }^{\circ} \mathrm{C}$ \\
\hline Cathode & LFP & $\sim 250$ \\
\cline { 2 - 3 } & LMO & $\sim 300$ \\
\cline { 2 - 3 } & NCA & $\sim 300$ \\
\cline { 2 - 3 } & LCO & $\sim 120$ \\
\cline { 2 - 3 } & NMC & $\sim 250-270$ \\
\hline \multirow{4}{*}{ Anode } & Ordinary graphite & $\sim 120$ \\
\cline { 2 - 3 } & Artificial graphite & $\sim 130$ \\
\hline
\end{tabular}

In addition to SOC and cell chemistry, the SOH of the cells also affects the onset temperature that triggers thermal runaway. For instance, Wu et al. (2018) analyzed NMC cells at five different capacity fade levels $(0 \%, 10 \%, 20 \%, 30 \%$, and $40 \%)$ and four SOC levels $(60 \%$, $80 \%, 100 \%$, and $120 \%$ ). They demonstrated that the onset temperatures decrease as the SOC level and capacity fade increase, showing that aged cells are more susceptible to thermal runaway than new cells.

\section{THERMAL BEHAVIOR OF LIBS: CHALLENGES, OPPORTUNITIES AND TRENDS}

The main challenges and opportunities related to the impact of the thermal behavior of LIBs on their performance and life cycle are related to pursuing efforts on mitigating aging, and providing strategies for minimizing the effect of fast-charging on increasing temperature gradients and cell heterogeneity. The BTMS design, the selection of anode materials, and fast-charging methods play a significant role in tackling both challenges. During cycling aging, the BTMS must overcome crucial challenges to maximize the lifetime of LIBs, such as (1) regulating the operating temperature within the desired range and ensuring the stability of the SEI on the cells, (2) keeping an even temperature among the cells to avoid developing different degradation paths, and (3) controlling temperature rise during fast-charging or high charge rates.

BTMS design. Significant research efforts have been dedicated to improving BTMS designs for LIBs. BTMS strategies that employ liquid are regarded as more efficient solutions than strategies employing air. For instance, oil and water can achieve up to three times larger heat transfer coefficients than air (Hu et al. 2020). In systems that use a liquid as a thermal medium, two types of liquids can be used: (1) directcontact liquid or dielectric liquid, and (2) indirect-contact liquid or conducting liquid, such as water, acetone and ethylene glycol. In combination with fin and plates, indirect-contact liquids are preferred over direct-contact due to its better thermal and safety performance ( $\mathrm{Li}$ and Zhu 2014). In liquid-based systems, the temperature distribution on the surface of the cell is more uniform compared to air-based systems. The uneven distribution of the temperature on cells would cause different degradation paths to occur; consequently, this cell-to-cell variation would affect the balancing strategies of the BMS, and would significantly reduce the reliability of the battery. BTMS designs, including mini-channel cold-plates (Panchal et al. 2017), have demonstrated to enhance liquid cooling systems by improving the 
temperature uniformity and minimizing temperature differences within the pack. Liquid-based systems are preferred over air-based BTMS because they are more efficient in keeping a uniform temperature, and they are also capable of controlling the temperature in hot weather, where air-based heat transfer is limited (Yang, 2017). On the other hand, coolants are preferred over refrigerants in liquid-based BTMSs, since a refrigerant-based system would add the challenge of not being able to heat the battery during winter.

Heat pipes (HP) are a relatively novel concept for BTMSs; they exhibit a very high thermal conductivity and operate based on heat transfer through evaporation (Huang et al. 2018, Guo et al. 2020). These systems can achieve a highly uniform temperature distribution on the surface of the battery. HPs are effective solutions for controlling the temperature at low C-rates (Zhao et al. 2015), lowering the limit of the maximum surface temperature from $50{ }^{\circ} \mathrm{C}$ to $40{ }^{\circ} \mathrm{C}$ (Nasir et al. 2018). Nevertheless, existing heat pipes designs for BTMS are not designed to dissipate larger amounts of generated heat from the battery pack at high C-rates (Deng et al. 2019). An improvement to this strategy is presented by Zhao et al. (2015), combining a wet cooling method with a heat pipe system, by cooling down the battery pack through water evaporation and phase change inside the heat pipe. This combined strategy showed experimental temperature differences within the pack lower than $1.5^{\circ} \mathrm{C}$. Some of the drawbacks of current flat designs of HPs include high cost and high volume, and these systems are not efficient for high current discharge rates (Deng et al., 2019). A recent HP design, consisting of an L-shaped HP combined with an aluminum plate, has been proposed by Deng et al. (2019) and tested for an 8 Ah battery under natural convection, forced ventilation, and HP with fins. The effect of high discharge rates, such as $50 \mathrm{~A}, 75 \mathrm{~A}$, and $100 \mathrm{~A}$, was observed in the battery temperature, which increased from $37{ }^{\circ} \mathrm{C}$ ambient temperature to $38.1{ }^{\circ} \mathrm{C}, 38.6{ }^{\circ} \mathrm{C}$, and $39.0^{\circ} \mathrm{C}$, respectively. In terms of uniformity, the corresponding maximum temperature differences of the battery were $0.8{ }^{\circ} \mathrm{C}, 1.4^{\circ} \mathrm{C}$, and $1.7^{\circ} \mathrm{C}$, respectively.

Passive BTMSs using PCMs are highly competitive due to its high efficiency and compactness (Santhanagopalan et al. 2015). PCMs are characterized by their attributes of absorbing or releasing a large amount of latent heat when the solid state changes to a liquid state or vice versa. In addition to the phase change temperature falling within the desired operating range of the battery, PCMs shall have low volume expansion, low cost, and be intrinsically safe (Bahiraei, 2017). In general, PCMs have low thermal conductivity. In order to reduce the thermal gradient inside the pack, several thermal management strategies have been proposed; nevertheless, the adoption of PCMs into ethylene glycol matrix has been referred to as the ideal option for improvement (Mo et al. 2016).

Liquid-to-vapor phase change systems, on the other hand, combine the advantage of high heat transfer rates offered by liquid-based systems and highly efficient passive BTMSs such as PCMs. The principle of these combined systems is boiling a liquid into vapor, using the maximum available heat dissipation (Al-Zareer et al. 2017). This technology has already been used in thermal management in several applications, such as air conditioning and quantum computing. Nevertheless, the feasibility of its implementation in BTMS for EVs has been recently evaluated using modeling and simulation, leading to promising results that should be experimentally validated. Further investigation of such technology is highly merited as it is projected to be one of the leading solutions to the thermal management of LIBs (AlZareer et al. 2017).

Fast-charging methods. The most common approach to battery charging is the combined constant-current (CC) and constant-voltage (CV) charging profiles, where the charger first applies a constant current until the battery reaches a defined voltage potential, from where the voltage is kept constant, and the current gradually decreases until full charge (Hoque et al. 2016).

Pulse charging is another method that also enables FC. In this method, pulses of current are sent to the battery, enhancing the charging time while considering battery heating, battery impedance, and polarization (Majid et al. 2017). Fast-charging is achieved by selecting the appropriate pulse frequency that minimizes the impedance. In principle, this method can decrease the amount of lithium plating in the anode. For instance, Amanor-Boadu et al. (2018) reported a lower capacity loss on lithium-ion polymer batteries at different temperatures $\left(0{ }^{\circ} \mathrm{C}, 23{ }^{\circ} \mathrm{C}\right.$, and $\left.45^{\circ} \mathrm{C}\right)$ than using $\mathrm{CC}-\mathrm{CV}$ charging. The main challenge in the development of pulse charging algorithms is the optimal selection of pulse attributes to ensure the optimal battery performance, such as the peak current amplitude, duty cycle, and frequency at different levels on the battery life cycle. This drawback limits the implementation of this method in electric vehicle applications (Majid et al. 2017).

Negative pulse charging has also been employed for FC, by imposing small discharges to the battery during the rest period of the pulse charging. This method minimizes the temperature rise of the cell and contributes to the periodic depolarization of the cell, allowing high charge rates (Zhifu et al. 2016), making it very promising. The negative pulse charging has not been tested in full-scale and long terms effects on the stability of electrodes, and the loss of active material due to overheating has not been studied yet.

Anode material selection. Research efforts have been oriented to the replacement of graphite anodes to minimize aging due to SEI formation and growth, and lithium plating, as well as minimizing intrinsic cell heterogeneity during the manufacturing process that could contribute to increasing temperature gradients among the cells. The most promising anode materials that have been tested for replacing graphite are graphene and transition element oxide-graphene, as described in Section 2.8. Silicon and transition metal oxides have a high theoretical capacity; nevertheless, their high volume change experienced during lithiation and delithiation causes loss of electrical connection and loss of active material (Wu et al. 2020). Also, these materials cause cracking and delamination of the SEI (Wu et al. 2020). Graphene, on the other hand, exhibits high capacity, but its use has been limited in LIBs due to its low initial Coulombic efficiency (Roselin et al. 2019). Graphene exhibits an improved thermo-electrochemical performance compared to graphite, including high reversible capacity, and lower aging rates (Wu et al. 2011). Hence, future efforts for anode material development and selection should consider capacity, Coulombic efficiency, minimization of loss of active material, and rate performance. Moreover, these materials should overcome the temperature rise caused by fast-charging and have a lower cost, compared to graphite. For example, Chang et al. (2017) developed a graphene-like-graphite (GLG) material for the anode that exhibits a high capacity of $608 \mathrm{mAh} / \mathrm{g}$ and upper voltage of $2 \mathrm{~V}$, and even higher capacity at C-rates of 6 and 10C than only graphite, as well as high stability during cycling.

\section{CONCLUDING REMARKS}

This paper reviewed the thermal behavior of lithium-ion batteries related to aging, heat generation, thermal management and thermal failure. The aging section summarized the main aging mechanisms in the anode and cathode of LIBs, focusing on the effect of the temperature on the degradation of different cell chemistries for calendar and cycling modes. The impact of the main stress factors on aging for LCO, NMC, NCA, LMO, LFP and LTO cell chemistries was qualitatively assessed. In calendar aging, NMC, LCO and LMO cells are more aging-sensitive in the high-temperature domain, compared to NCA and LFP cells. In cycling aging, the impact of additional stress factors on aging, such as high C-rates, showed that NCA cells are more suitable for fast-charging than LFP and NMC cells. Three temperature domains were defined based on the aging rate that cells can experience: (1) low-temperature domain $\left(<20^{\circ} \mathrm{C}\right)$, where lithium-plating is the primary degradation mechanism; (2) high-temperature domain $\left(>40{ }^{\circ} \mathrm{C}\right.$ and less than the onset temperature promoting thermal runaway), where 
SEI is the primary degradation mechanism; and (3) an intermediate domain, where the battery performance and lifetime are maximized. We reviewed modeling approaches for predicting aging, including electrochemical models, ECMs, and models based on data correlating stress factors with aging indicators. We classified and described the efforts on mitigating aging, falling into three main categories: (1) BTMS design, (2) minimizing the impact of stress factors due to user patterns, and (3) selection of anode material. Finally, we tackled the ongoing efforts on fast-charging as a strategy in reducing the range anxiety of potential consumers of EVs and its effect on aging due to temperature rise, and increasing cell heterogeneity.

In terms of heat generation and surface temperature variation in LIBs, the sources of heat generation, as well as the stress factors that influence the reversible and irreversible heating of LIBs, were reviewed. All cell chemistries showed different patterns in the evolution of the surface temperature, being NMC cathodes the ones that generate more heat and non-uniform heat generation.

The challenges of both intrinsic thermal behavior and cell responses to extrinsic factors can be tackled with BTMS strategies for cooling and heating LIBs. A quick overview of the main strategies employed by BTMSs was provided, as well as and coupling approaches with LIB degradation models. We also reviewed the leading causes of thermal runaway and briefly compared them among different cell chemistries, showing that NCA and LMO cells experienced the highest onset temperatures, followed by NMC and LFP cells.

The last section of this paper identified the main challenges and opportunities related to the impact of the thermal behavior of LIBs on their performance and life cycle. These challenges fall into two categories: (1) pursuing efforts on mitigating aging, and (2) providing strategies for minimizing the effect of fast-charging on higher temperature gradients and cell heterogeneity. The opportunities to mitigate these challenges include (1) BTMS design, (2) fast-charging methods, and (3) anode material selection.

\section{ACKNOWLEDGMENTS}

The authors would like to thank the Natural Sciences and Engineering Research Council of Canada (NSERC) for their financial support towards this research.

\section{NOMENCLATURE}

$\begin{array}{ll}a_{s} i & \text { Area-scaled reaction rate }(\mathrm{J} / \mathrm{s}) \\ A & \text { Pre-exponential factor }(1 / \mathrm{s}) \\ E_{A} & \text { Activation energy }(\mathrm{J} / \mathrm{mol} \mathrm{K}) \\ \mathrm{I} & \text { Charge/discharge current }(\mathrm{A}) \\ \mathrm{q} & \text { Heat generation rate }(\mathrm{J} / \mathrm{s}) \\ \mathrm{R} & \text { Constant }(8.314 \mathrm{~J} / \mathrm{mol}) \\ \mathrm{T} & \text { Temperature }(\mathrm{K}) \\ \mathrm{U} & \text { Equilibrium value for the potential } \\ \mathrm{V} & \text { Voltage }\end{array}$

\section{ABBREVIATIONS}

$\begin{array}{ll}\text { AC } & \text { Alternative current } \\ \text { ARC } & \text { Accelerating rate calorimetry } \\ \text { BMS } & \text { Battery management system } \\ \text { BOL } & \text { Beginning-of-life } \\ \text { BTMS } & \text { Battery thermal management system } \\ \text { CC } & \text { Constant-current } \\ \text { CSBC } & \text { Copper slug battery calorimetry } \\ \text { CV } & \text { Constant-voltage } \\ \text { DFT } & \text { Density functional theory } \\ \text { DOD } & \text { Depth-of-discharge } \\ \text { DSC } & \text { Differential scanning calorimetry }\end{array}$

$\begin{array}{ll}\text { EC } & \text { Ethylene carbonate } \\ \text { ECM } & \text { Equivalent circuit model } \\ \text { EDC } & \text { Ethylene dicarbonate } \\ \text { EIS } & \text { Electrochemical impedance spectroscopy } \\ \text { EOL } & \text { End-of-life } \\ \text { EV } & \text { Electric vehicle } \\ \text { FC } & \text { Fast-charging } \\ \text { GLG } & \text { Graphene-like-graphite } \\ \text { HP } & \text { Heat pipes } \\ \text { LCO } & \text { Lithium cobalt oxide } \\ \text { LFP } & \text { Lithium iron phosphate } \\ \text { LIB } & \text { Lithium-ion battery } \\ \text { LMO } & \text { Lithium manganese oxide } \\ \text { LTO } & \text { Lithium titanate oxide } \\ \text { MD } & \text { Molecular dynamics } \\ \text { NCA } & \text { Nickel cobalt aluminum oxide } \\ \text { NMC } & \text { Nickel manganese cobalt } \\ \text { PC } & \text { Propylene carbonate } \\ \text { PCM } & \text { Phase change material } \\ \text { ref } & \text { Reference } \\ \text { RUL } & \text { Remaining-useful-life } \\ \text { SEI } & \text { Solid electrolyte interface } \\ \text { SOC } & \text { State-of-charge } \\ \text { SOH } & \text { State-of-health } \\ \text { SPM } & \text { Single particle model } \\ & \\ \text { Greek } & \text { Symbols } \\ \nabla \phi & \text { Voltage gradient }\left(\mathrm{J} / \mathrm{m}^{3} \cdot \mathrm{K}\right) \\ \sigma & \text { Electronic conductivity }(\mathrm{S} / \mathrm{m}) \\ \eta & \text { Overpotential } \\ \end{array}$

\section{REFERENCES}

Abada, S., Marlair, G., Lecocq, A., Petit, M., Sauvant-Moynot, V., and Huet F., 2016. "Safety focused modeling of lithium-ion batteries: A review". Journal of Power Sources, 306, 178-192. https://doi.org/10.1016/j.jpowsour.2015.11.100

Afshar, S., 2017. "Lithium-ion battery SOC estimation". University of Waterloo, PhD Dissertation.

Agubra, V., and Fergus, J., 2013. "Lithium Ion Battery Anode Aging Mechanisms". Materials, 6(4), 1310-1325.

https://doi.org/10.3390/ma6041310

Al-Zareer, M., Dincer, I., and Rosen, M. A., 2017. "Novel thermal management system using boiling cooling for high-powered lithium-ion battery packs for hybrid electric vehicles". Journal of Power Sources, 363, 291-303.

https://doi.org/10.1016/j.jpowsour.2017.07.067

Al-Zareer, M., Dincer, I., and Rosen, M. A., 2018. "A review of novel thermal management systems for batteries". International Journal of Energy Research, 42(10), 3182-3205. https://doi.org/10.1002/er.4095

Al-Zareer, M., Dincer, I., and Rosen, M. A., 2019. "Comparative assessment of new liquid-to-vapor type battery cooling systems". Energy, 188 (1), 116010. https://doi.org/10.1016/j.energy.2019.116010

An, S. J., Li, J., Daniel, C., Mohanty, D., Nagpure, S., and Wood, D. L., 2016. "The state of understanding of the lithium-ion-battery graphite solid electrolyte interphase (SEI) and its relationship to formation cycling". Carbon, 105, 52-76.

https://doi.org/10.1016/j.carbon.2016.04.008 
Arora, P.,1998. "Capacity Fade Mechanisms and Side Reactions in Lithium-Ion Batteries." Journal of The Electrochemical Society, 145 (10), 3647-3667. https://doi.org/10.1149/1.1838857

Aurbach, D., 1996. “A Comparative Study of Synthetic Graphite and Li Electrodes in Electrolyte Solutions Based on Ethylene CarbonateDimethyl Carbonate Mixtures". Journal of The Electrochemical Society, 143(12), 3809-3820.

https://doi.org/10.1149/1.1837300

Aurbach, D., Levi, M. D., Levi, E., and Schechter, A., 1997. "Failure and Stabilization Mechanisms of Graphite Electrodes. The Journal of Physical Chemistry, 101(10), 2195-2206.

https://doi.org/10.1021/jp962815t

Bahiraei, F., 2017. "Thermal management of lithium-ion battery modules for electric vehicles". University of Windsor, Doctoral Thesis.

Balagopal, B., Huang, C. S., and Chow, M.-Y., 2018. "Effect of calendar ageing on SEI growth and its impact on electrical circuit model parameters in Lithium ion batteries". 2018 IEEE International Conference on Industrial Electronics for Sustainable Energy Systems (IESES).

https://doi.org/10.1109/ieses.2018.8349846

Bandhauer, T. M., Garimella, S., and Fuller, T. F., 2011. "A Critical Review of Thermal Issues in Lithium-Ion Batteries". Journal of The Electrochemical Society, 158 (3), R1-R25.

https://doi.org/10.1149/1.3515880

Barré, A., Deguilhem, B., Grolleau, S., Gérard, M., Suard, F., and Riu, D., 2013. "A review on lithium-ion battery ageing mechanisms and estimations for automotive applications". Journal of Power Sources, 241, 680-689.

https://doi.org/10.1016/j.jpowsour.2013.05.040

Bauer, M., Guenther, C., Kasper, M., Petzl, M., and Danzer, M. A., 2015. "Discrimination of degradation processes in lithium-ion cells based on the sensitivity of aging indicators towards capacity loss". Journal of Power Sources, 283, 494-504.

https://doi.org/10.1016/j.jpowsour.2015.02.130

Bernardi D., 1985. "A General Energy Balance for Battery Systems". Journal of The Electrochemical Society, 132(1), 5-12. https://doi.org/10.1149/1.2113792

Bhaskar, A., Deepa, M., Rao, T., and Varadaraju, U., 2012. "Enhanced nanoscale conduction capability of a MoO2/Graphene composite for high performance anodes in lithium ion batteries". Journal of Power Sources, 216, 169-178.

https://doi.org/10.1016/j.jpowsour.2012.05.050

Birkl, C. R., Roberts, M. R., Mcturk, E., Bruce, P. G., and Howey, D. A., 2017. "Degradation diagnostics for lithium ion cells". Journal of Power Sources, 341, 373-386.

https://doi.org/10.1016/j.jpowsour.2016.12.011

Bryngelsson, H., Stjerndahl, M., Gustafsson, T., and Edström, K. ,2007. "How dynamic is the SEI?", Journal of Power Sources, 174(2), 970975.

https://doi.org/10.1016/j.jpowsour.2007.06.050

Cao, F., Barsukov, I. V., Bang, H. J., Zaleski, P., and Prakash, J., 2000 "Evaluation of Graphite Materials as Anodes for Lithium-Ion Batteries". Journal of The Electrochemical Society, 147(10), 35793583.

https://doi.org/10.1149/1.1393942

Chang, Q., Okamoto, Y., Tamura, N., Tsuji, M., Maruyama, S., and Matsuo, Y., 2017 "Graphene-like-graphite as fast-chargeable and highcapacity anode materials for lithium ion batteries". Nature - Scientific Reports, 7, 1-14.

https://doi.org/10.1038/s41598-017-14504-8
Chen, C.-F., Verma, A., and Mukherjee, P. P., 2017. "Probing the Role of Electrode Microstructure in the Lithium-Ion Battery Thermal Behavior". Journal of The Electrochemical Society, 164 (11), E3146E3158. https://doi.org/10.1149/2.0161711jes

Christensen, J., and Newman, J., 2005. "Cyclable Lithium and Capacity Loss in Li-Ion Cells". Journal of The Electrochemical Society, 152 (4), A818-A829.

https://doi.org/10.1149/1.1870752

Dalverny, A.-L., Filhol, J.-S., and Doublet, M.-L., 2011. "Interface electrochemistry in conversion materials for Li-ion batteries". Journal of Materials Chemistry, 21, 10134-10142.

https://doi.org/10.1039/c0jm04202a

Deng, S., Li, K., Xie, Y., Wu, C., Wang, P., Yu, M., Li, B., and Zheng, J., 2019. "Heat Pipe Thermal Management Based on High-Rate Discharge and Pulse Cycle Tests for Lithium-Ion Batteries". Energies, 12(16), 3143.

https://doi.org/ 10.3390/en12163143

Devie A., Dubarry M., and Liaw B. Y., 2014. "Diagnostics of Li-Ion Commercial Cells - Experimental Case Studies". ECS Transactions, 58, 193-205.

https://doi.org/10.1149/05848.0193ecst

Doyle, M., and Newman, J., 1995. "Modeling the performance of rechargeable lithium-based cells: design correlations for limiting cases". Journal of Power Sources, 54, 46-51.

https://doi.org/10.1016/0378-7753(94)02038-5

Dubarry, M., Qin, N., Brooker, P., 2018. "Calendar aging of commercial Li-ion cells of different chemistries - A review". Current Opinion in Electrochemistry, 9, 106-113.

https://doi.org/10.1016/j.coelec.2018.05.023

Ecker, M., Gerschler, J. B., Vogel, J., Käbitz, S., Hust, F., Dechent, P., and Sauer, D. U., 2012. "Development of a lifetime prediction model for lithium-ion batteries based on extended accelerated aging test data". Journal of Power Sources, 215, 248-257. https://doi.org/10.1016/j.jpowsour.2012.05.012

Eddahech, A., Briat, O., and Vinassa, J.-M., 2015. "Performance comparison of four lithium-ion battery technologies under calendar aging". Energy, 84, 542-550.

https://doi.org/10.1016/j.energy.2015.03.019

Edström, K., Herstedt, M., and Abraham, D. P.,2006. "A new look at the solid electrolyte interphase on graphite anodes in Li-ion batteries". Journal of Power Sources, 153, 380-384.

https://doi.org/10.1016/j.jpowsour.2005.05.062

Fan, L., Khodadadi, J., and Pesaran, A., 2013. "A parametric study on thermal management of an air-cooled lithium-ion battery module for plug-in hybrid electric vehicles". Journal of Power Sources, 238, 301312 .

https://doi.org/10.1016/j.jpowsour.2013.03.050

Feng, X., Sun, J., Ouyang, M., He, X., Lu, L., Han, X., and Peng, H., 2014. "Characterization of large format lithium ion battery exposed to extremely high temperature". Journal of Power Sources, 272, 457-467. https://doi.org/10.1016/j.jpowsour.2014.08.094

Feng, X., Zheng, S., Ren, D., He, X., Wang, L., Liu, X., and Ouyang, M., 2019. "Key Characteristics for Thermal Runaway of Li-ion Batteries”. Energy Procedia, 158, 4684-4689. https://doi.org/10.1016/j.egypro.2019.01.736

Galatro, D., Da Silva, C., Romero, D.A., Trescases, O., and Amon, C.H., 2020. "Challenges in Data-Based Degradation Models for Lithium-ion Batteries”, International Journal of Energy Research, 44, 3954-3975.

https://doi.org/10.1002/er.5196 
Gismero, A., Stroe, D.-I., and Schaltz, E., 2019. "Calendar Aging Lifetime Model for NMC-based Lithium-ion Batteries Based on EIS Measurements". 2019 Fourteenth International Conference on Ecological Vehicles and Renewable Energies (EVER). https://doi.org/10.1109/ever.2019.8813635

Golubkov, A. W., Scheikl, S., Planteu, R., Voitic, G., Wiltsche, H., Stangl, C., and Hacker, V., 2015. "Thermal runaway of commercial $18650 \mathrm{Li}$-ion batteries with LFP and NCA cathodes - impact of state of charge and overcharge". RSC Advances, 5, 57171-57186.

https://doi.org/10.1039/c5ra05897j

Goutam, S., Timmermans, J.-M., Omar, N., Bossche, P., and Mierlo, J. V., 2015. "Comparative Study of Surface Temperature Behavior of Commercial Li-Ion Pouch Cells of Different Chemistries and Capacities by Infrared Thermography". Energies, 8, 8175-8192.

https://doi.org/10.3390/en8088175

Grolleau, S., Delaille, A., Gualous, H., Gyan, P., Revel, R., Bernard, J., and Peter, J., 2014. "Calendar aging of commercial graphite/LiFePO4 cell - Predicting capacity fade under time dependent storage conditions". Journal of Power Sources, 255, 450-458.

https://doi.org/10.1016/j.jpowsour.2013.11.098

Guha, A., and Patra, A., 2018. "State of Health Estimation of LithiumIon Batteries Using Capacity Fade and Internal Resistance Growth Models". IEEE Transactions on Transportation Electrification, 4(1), $135-146$

https://doi.org/10.1109/tte.2017.2776558

Guo, H., Xianbing, J. and Jinliang, X., 2020. "Research and Development of Loop Heat Pipe - A Review". Frontiers in Heat and Mass Transfer, 14(14).

https://doi.org/10.5098/hmt.14.14

Han, X., Ouyang, M., Lu, L., Li, J., Zheng, Y., and Li, Z., 2014. “A comparative study of commercial lithium ion battery cycle life in electrical vehicle: Aging mechanism identification". Journal of Power Sources, 251, 38-54.

https://doi.org/10.1016/j.jpowsour.2013.11.029

Harting, N., Wolff, N., and Krewer, U., 2018. "Identification of Lithium Plating in Lithium-Ion Batteries using Nonlinear Frequency Response Analysis (NFRA)". Electrochimica Acta, 281, 378-385.

https://doi.org/10.1016/j.electacta.2018.05.139

Hoque, M. M., Hannan, M. A., and Mohamed, A., 2016. "Optimal CCCV charging of lithium-ion battery for charge equalization controller". 2016 International Conference on Advances in Electrical, Electronic and Systems Engineering (ICAEES).

https://doi.org/10.1109/icaees.2016.7888119

Hu, X., Zheng, Y., Howey, D. A., Perez, H., Foley, A., and Pecht, M., 2020. "Battery warm-up methodologies at subzero temperatures for automotive applications: Recent advances and perspectives". Progress in Energy and Combustion Science, 77, 100806.

https://doi.org/10.1016/j.pecs.2019.100806

Huang, Q., Li, X., Zhang, G., Zhang, J., He, F., and Li, Y., 2018."Experimental investigation of the thermal performance of heat pipe assisted phase change material for battery thermal management system". Applied Thermal Engineering, 141, 1092-1100.

https://doi.org/10.1016/j.applthermaleng.2018.06.048

Jaguemont, J., Boulon, L., Venet, P., Dube, Y., and Sari, A., 2016. "Lithium-Ion Battery Aging Experiments at Subzero Temperatures and Model Development for Capacity Fade Estimation". IEEE Transactions on Vehicular Technology, 65, 4328-4343.

https://doi.org/10.1109/tvt.2015.2473841

Jalkanen, K., Karppinen, J., Skogström, L., Laurila, T., Nisula, M., and Vuorilehto, K., 2015. "Cycle aging of commercial NMC/graphite pouch cells at different temperatures". Applied Energy, 154, 160-172.

https://doi.org/10.1016/j.apenergy.2015.04.110
Jiang, F., and Peng, P., 2016. "Elucidating the Performance Limitations of Lithium-ion Batteries due to Species and Charge Transport through Five Characteristic, Parameters". Scientific Reports, 6. https://doi.org/10.1038/srep32639

Jiang, F., Peng P., and Sun, Y., 2013. "Thermal analyses of LiFePO4 /graphite battery discharge processes". Journal of Power Sources, 243, 181-194.

https://doi.org/10.1016/j.jpowsour.2013.05.089

Kannan, D. R. R., Terala, P. K., Moss, P. L., and Weatherspoon, M. H., 2018. "Analysis of the Separator Thickness and Porosity on the Performance of Lithium-Ion Batteries". International Journal of Electrochemistry, 2018, 1-7.

https://doi.org/10.1155/2018/1925708

Kantharaj, R., and Marconnet, A. M., 2019. "Heat Generation and Thermal Transport in Lithium-Ion Batteries: A Scale-Bridging Perspective". Nanoscale and Microscale Thermophysical Engineering, 23, 128-156.

https://doi.org/10.1080/15567265.2019.1572679

Karimi, G., and Li, X., 2012. "Thermal management of lithium-ion batteries for electric vehicles". International Journal of Energy Research, 37(1), 13-24.

https://doi.org/10.1002/er.1956

Kassem, M., Bernard, J., Revel, R., Pélissier, S., Duclaud, F., and Delacourt, C., 2012. "Calendar aging of a graphite/LiFePO4 cell". Journal of Power Sources, 208, 296-305.

https://doi.org/10.1016/j.jpowsour.2012.02.068

Keil, P., and Jossen, A., 2015. "Aging of Lithium-Ion Batteries in Electric Vehicles: Impact of Regenerative Braking”. World Electric Vehicle Journal, 7(1), 41-51. https://doi.org/10.3390/wevj7010041

Keil, P., Schuster, S.F., Wilhelm, J., Travi, J., Hauser, A., Karl, R.C., and Jossen, A., 2016. "Calendar aging of lithium-ion batteries". Journal of the Electrochemical Society, 163 (9), A1872-A1880.

https://doi.org/10.1149/2.0411609jes

Kim, H.-K., Kim, C.-J., Kim, C.-W., and Lee, K.-J., 2018. "Numerical analysis of accelerated degradation in large lithium-ion batteries". Computers \& Chemical Engineering, 112, 82-91.

https://doi.org/10.1016/j.compchemeng.2017.12.019

Kim, J., Oh, J., and Lee, H., 2019. "Review on battery thermal management system for electric vehicles". Applied Thermal Engineering, 149, 192-212.

https://doi.org/10.1016/j.applthermaleng.2018.12.020

Kindermann, F. M., Keil, J., Frank, A., and Jossen, A., 2017. “A SEI Modeling Approach Distinguishing between Capacity and Power Fade". Journal of The Electrochemical Society, 164(12), E287-E294. https://doi.org/10.1149/2.0321712jes

Kvasha, A., Gutiérrez, C., Osa, U., Meatza, I. D., Blazquez, J. A., Macicior, H., and Urdampilleta, I., 2018. "A comparative study of thermal runaway of commercial lithium ion cells". Energy, 159, 547557.

https://doi.org/10.1016/j.energy.2018.06.173

Latz, A., and Zausch, J., 2015. "Thermal-Electrochemical Lithium-Ion Battery Simulations on Microstructure and Porous Electrode Scale". ECS Transactions, 69, 75-81. https://doi.org/10.1149/06901.0075ecst

Legrand, N., Knosp, B., Desprez, P., Lapicque, F., and Raël, S., 2014. "Physical characterization of the charging process of a Li-ion battery and prediction of Li plating by electrochemical modelling". Journal of Power Sources, 245, 208-216.

https://doi.org/10.1016/j.jpowsour.2013.06.130 
Leng, F., Tan, C. M., and Pecht, M., 2015. "Effect of Temperature on the Aging rate of Li Ion Battery Operating above Room Temperature". Scientific Reports, 5. https://doi.org/10.1038/srep12967

Li, J., and Zhu, Z, A., 2014. "Battery thermal management systems of electric vehicles". Chalmers University of Technology, Master of Science Thesis.

Lin, C., Tang, A., Mu, H., Wang, W., and Wang, C., 2015. Aging Mechanisms of Electrode Materials in Lithium-Ion Batteries for Electric Vehicles. Journal of Chemistry, 2015, 1-11.

https://doi.org/10.1155/2015/104673

Lin, C., Wang, F., Fan, B., Ren, S., Zhang, Y., Han, L., and Xu, S., 2017. "Comparative study on the heat generation behavior of lithiumion batteries with different cathode materials using accelerating rate calorimetry". Energy Procedia, 142, 3369-3374.

https://doi.org/10.1016/j.egypro.2017.12.472

Liu, Q., Du, C., Shen, B., Zuo, P., Cheng, X., Ma, Y., and Gao, Y., 2016. "Understanding undesirable anode lithium plating issues in lithium-ion batteries". RSC Advances, 6(91), 88683-88700.

https://doi.org/10.1039/c6ra19482f

Liu, X., Wu, Z., Stoliarov, S. I., Denlinger, M., Masias, A., and Snyder, K., 2016. "Heat release during thermally-induced failure of a lithium ion battery: Impact of cathode composition". Fire Safety Journal, 85, $10-22$.

https://doi.org/10.1016/j.firesaf.2016.08.001

Luo, R.P., Lyu, W.Q., Wen, K.C., and He, W.D., 2018. "Overview of Graphene as Anode in Lithium-Ion Batteries". Journal of Electronic Science and Technology, 16, 57-68.

https://doi.org/ 10.11989/JEST.1674-862X.6032519

Lutsey, N., Searle, S., Chambliss, S., and Bandivadekar, A., 2015. "Assessment of leading electric vehicle promotion activities in United States cities". http://theicct.org/leading-us-city-electric-vehicleactivities.

Madani, S. S., Schaltz, E., and Kær, S. K., 2018."Study of Temperature Impacts on a Lithium-Ion Battery Thermal Behaviour by Employing Isothermal Calorimeter". ECS Transactions, 87, 295-305. https://doi.org/10.1149/08701.0295ecst

Majid, N., Hafiz, S., Arianto, S., Yuono, R. Y., and Astuti, E. T., Prihandoko B., 2017. "Analysis of effective pulse current charging method for lithium ion battery". Journal of Physics: Conference Series, 817, 012008 .

https://doi.org/10.1088/1742-6596/817/1/012008

Mao, C., Wood, M., David, L., An, S. J., Sheng, Y., Du, Z, and Wood, D. L., 2018. "Selecting the Best Graphite for Long-Life, High-Energy Li-Ion Batteries". Journal of The Electrochemical Society, 165(9), A1837-A1845.

https://doi.org/10.1149/2.1111809jes

Mo, S., Zhu, K., Yin, T., Chen, Y., and Cheng, Z., 2016. "Phase change characteristics of ethylene glycol solution-based nanofluids for subzero thermal energy storage". International Journal of Energy Research, 41(1), 81-91.

https://doi.org/10.1002/er.3599

Morigaki, K.-I., and Ohta, A., 1998. "Analysis of the surface of lithium in organic electrolyte by atomic force microscopy, Fourier transform infrared spectroscopy and scanning auger electron microscopy". Journal of Power Sources, 76 (2), 159-166.

https://doi.org/10.1016/s0378-7753(98)00151-7

Mussa, Y., Ahmed, F., Abuhimd, H., Arsalan, M., and Alsharaeh, E., 2019. "Enhanced Electrochemical performance at high temperature of Cobalt Oxide/Reduced Graphene Oxide Nanocomposites and its application in lithium-ion batteries". Scientific Reports, 9(1). https://doi.org/10.1038/s41598-018-37032-5

Narula, A., 2014. "Modeling of ageing of lithium-ion battery at low temperatures". Chalmers University of Technology, Master of Science Thesis.

Nasir, F. M., Abdullah, M. Z., and Ismail, M. A., 2018. "Experimental Investigation On The Heat Transfer Performance Of Heat Pipes In Cooling Hev Lithium-Ion Batteries". Heat Transfer Research, 49(17), 1745-1760. https://doi.org/10.1615/heattransres.2018021524

Needell, Z. A., Mcnerney, J., Chang, M. T., and Trancik, J. E., 2016. "Potential for widespread electrification of personal vehicle travel in the United States". Nature Energy, 1(9). https://doi.org/10.1038/nenergy.2016.112

Neubauer, J., and Wood, E., 2014. "Thru-life impacts of driver aggression, climate, cabin thermal management, and battery thermal management on battery electric vehicle utility", Journal of Power Sources. 259, 262-275.

https://doi.org/10.1016/j.jpowsour.2014.02.083

Newman J., and Tiedemann, W., 1975. "Porous-electrode theory with battery applications". AIChE Journal, 21, 25-41.

https://doi.org/10.1002/aic.690210103

Nguyen, T. T. D., Abada, S., Lecocq, A., Bernard, J., Petit, M., Marlair, G., Grugeon, S., and Laruelle, S., 2019. Understanding the Thermal Runaway of Ni-Rich Lithium-Ion Batteries. World Electric Vehicle Journal, 10(4), 79. https://doi.org/10.3390/wevi10040079

Orr, B., Singh, R., Phan, T.L., and Mochizuki, M., 2019, "Transient Modelling of an EV Inverter Heat Sink With PCM", Frontiers in Heat and Mass Transfer, 13, 1

http://dx.doi.org/10.5098/hmt.13.1

Palacín, M. R., 2018. "Understanding ageing in Li-ion batteries: a chemical issue". Chemical Society Reviews, 47(13), 4924-4933. https://doi.org/10.1039/c7cs00889a

Panchal, S., Khasow, R., and Dincer, I., Agelin-Chaab M., Fraser R., Fowler M., 2017. "Thermal design and simulation of mini-channel cold plate for water cooled large sized prismatic lithium-ion battery". Applied Thermal Engineering, 122, 80-90.

https://doi.org/10.1016/j.applthermaleng.2017.05.010

Parekh, M. H., Sediako, A. D., Naseri, A., Thomson, M. J., and Pol, V. G., 2019. "In Situ Mechanistic Elucidation of Superior Si-C-Graphite Li-Ion Battery Anode Formation with Thermal Safety Aspects". Advanced Energy Materials, 10 (2), 1902799.

https://doi.org/10.1002/aenm.201902799

Park, M.-H., Noh, M., Lee, S., Ko, M., Chae, S., Sim, S., Choi, S., Kim, H., Nam, H., Park, S., and Cho, J., 2014. "Flexible High-Energy Li-Ion Batteries with Fast-Charging Capability". Nano Letters, 14(7), 40834089.

https://doi.org/10.1021/nl501597s

Pasquier, A. D., 1998. "Differential Scanning Calorimetry Study of the Reactivity of Carbon Anodes in Plastic Li-Ion Batteries". Journal of The Electrochemical Society, 145 (2), 472-477.

https://doi.org/10.1149/1.1838287

Peled, E., and Menkin, S., 2017. "Review-SEI: Past, Present and Future". Journal of The Electrochemical Society, 164(7), A1703A1719.

https://doi.org/10.1149/2.1441707jes

Pesaran, A., and Keyser, M., 2001. "Thermal characteristics of selected EV and HEV batteries". Sixteenth Annual Battery Conference on Applications and Advances. Proceedings of the Conference (Cat. No.01TH8533).

https://doi.org/10.1109/bcaa.2001.905129 
Petzl, M., and Danzer, M. A., 2014. "Nondestructive detection, characterization, and quantification of lithium plating in commercial lithium-ion batteries". Journal of Power Sources, 254, 80-87. https://doi.org/10.1016/j.jpowsour.2013.12.060

Petzl, M., Kasper, M., and Danzer, M. A.,2015. "Lithium plating in a commercial lithium-ion battery - A low-temperature aging study". Journal of Power Sources, 275, 799-807.

https://doi.org/10.1016/j.jpowsour.2014.11.065

Pinson, M. B., and Bazant, M. Z., 2012. "Theory of SEI Formation in Rechargeable Batteries: Capacity Fade, Accelerated Aging and Lifetime Prediction". Journal of The Electrochemical Society, 160 (2), A243-A250.

https://doi.org/10.1149/2.044302jes

Qi, W., Shapter, J. G., Wu, Q., Yin, T., Gao, G., and Cui, D., 2017. "Nanostructured anode materials for lithium-ion batteries: principle, recent progress and future perspectives". Journal of Materials Chemistry A, 5(37), 19521-19540.

https://doi.org/10.1039/c7ta05283a

Rao, L., 1997. "Heat-Generation Rate and General Energy Balance for Insertion Battery Systems". Journal of The Electrochemical Society, 144 (8), 2697-2704.

https://doi.org/10.1149/1.1837884

Rao, Z., Qian, Z., Kuang, Y., and Li, Y., 2017. "Thermal performance of liquid cooling based thermal management system for cylindrical lithium-ion battery module with variable contact surface". Applied Thermal Engineering, 123, 1514-1522.

https://doi.org/10.1016/j.applthermaleng.2017.06.059

Rauhala, T., Jalkanen, K., Romann ,T., Lust, E., Omar, N., and Kallio, T., 2018. "Low-temperature aging mechanisms of commercial graphite/LiFePO4 cells cycled with a simulated electric vehicle load profile-A post-mortem study". Journal of Energy Storage, 20, 344356.

https://doi.org/10.1016/j.est.2018.10.007

Rohr, S., Müller, S., Baumann, M., Kerler, M., Ebert, F., Kaden, D., and Lienkamp, M., 2017. Quantifying Uncertainties in Reusing Lithium-Ion Batteries from Electric Vehicles. Procedia Manufacturing, 8, 603-610.

https://doi.org/10.1016/j.promfg.2017.02.077

Rumpf, K., Rheinfeld, A., Schindler, M., Keil, J., Schua, T., and Jossen, A., 2018. "Influence of Cell-to-Cell Variations on the Inhomogeneity of Lithium-Ion Battery Modules". Journal of The Electrochemical Society, 165 (11), A2587-A2607.

https://doi.org/10.1149/2.0111811jes

Safdari, M., Ahmadi, R., and Sadeghzadeh, S., 2020. "Numerical investigation on PCM encapsulation shape used in the passive-active battery thermal management. Energy, 193, 116840.

https://doi.org/10.1016/j.energy.2019.116840

Santhanagopalan, S., Kim, G.-H., Keyers, M., Pesaran, A. A., Smith, K., and Neubauer, J., 2015. "Design and analysis of large lithium-Ion battery systems". Boston: Artech House.

Schimpe, M., Kuepach, M. E. V., Naumann, M., Hesse, H. C., Smith, K., and Jossen, A., 2018. "Comprehensive Modeling of TemperatureDependent Degradation Mechanisms in Lithium Iron Phosphate Batteries.". Journal of The Electrochemical Society, 165 (2), A181A193.

https://doi.org/10.1149/2.1181714jes

Shi, L., and Zhao, T. , 2017. "Recent advances in inorganic 2D materials and their applications in lithium and sodium batteries". Journal of Materials Chemistry A, 5, 3735-3758.

https://doi.org/10.1039/c6ta09831b
Smith, K., Saxon, A., Keyser, M., Lundstrom, B., Cao, Z., and Roc, A., 2017. "Life prediction model for grid-connected Li-ion battery energy storage system". 2017 American Control Conference (ACC).

https://doi.org/10.23919/acc.2017.7963578

Song, J., Yu, Z., Gordin, M. L., Hu, S., Yi, R., Tang, D., and Wang, D., 2014. "Chemically Bonded Phosphorus/Graphene Hybrid as a High Performance Anode for Sodium-Ion Batteries". Nano Letters, 14, 6329 6335. https://doi.org/10.1021/n1502759z

Tahmasbi, A. A., Kadyk, T., and Eikerling, M. H., 2017. Statistical Physics-Based Model of Solid Electrolyte Interphase Growth in Lithium Ion Batteries. Journal of The Electrochemical Society, 164 (6), A1307-A1313. https://doi.org/10.1149/2.1581706jes

Takada, K., 2013. "Progress and prospective of solid-state lithium batteries". Acta Materialia, 61(3), 759-770. https://doi.org/10.1016/j.actamat.2012.10.034

Thomas, K. E., and Newman, J., 2003. "Thermal Modeling of Porous Insertion Electrodes". Journal of The Electrochemical Society, 150 (2), A176-A192.

https://doi.org/10.1149/1.1531194

Tippmann, S., Walper, D., Balboa, L., Spier, B., and Bessler, W. G., 2014. "Low-temperature charging of lithium-ion cells part I: Electrochemical modeling and experimental investigation of degradation behavior". Journal of Power Sources, 252, 305-316. https://doi.org/10.1016/j.jpowsour.2013.12.022

Tomaszewska, A., Chu, Z., Feng, X., O’Kane, S., Liu, X., Chen, J., Ji C., Endler, E., Li, R., Liu, L., Li, Y., Zheng, S., Vetterlein, S., Gao, M., Du, J., Parkes, M., Ouyang, M., Marinescu, M., Offer, G., and Wu, B., 2019. "Lithium-ion battery fast charging: A review". eTransportation, 1. https://doi.org/10.1016/j.etran.2019.100011

Verma, P., Maire, P., and Novák, P., 2010. "A review of the features and analyses of the solid electrolyte interphase in Li-ion batteries". Electrochimica Acta, 55, 6332-6341.

https://doi.org/10.1016/j.electacta.2010.05.072

Waag, W., Käbitz, S., and Sauer, D. U., 2013. "Experimental investigation of the lithium-ion battery impedance characteristic at various conditions and aging states and its influence on the application". Applied Energy, 102, 885-897.

https://doi.org/10.1016/j.apenergy.2012.09.030

Wagemaker, M., Singh, D. P., Borghols, W. J., Lafont, U., Haverkate, L., Peterson, V. K., and Mulder, F. M., 2011. "Dynamic Solubility Limits in Nanosized Olivine LiFePO4". Journal of the American Chemical Society, 133, 10222-10228.

https://doi.org/10.1021/ja2026213

Waldmann, T., Wilka, M., Kasper, M., Fleischhammer, M., and Wohlfahrt-Mehrens, M., 2014. "Temperature dependent ageing mechanisms in Lithium-ion batteries - A Post-Mortem study". Journal of Power Sources, 262, 129-135.

https://doi.org/10.1016/j.jpowsour.2014.03.112

Wang, J., Liu, P., Hicks-Garner, J., Sherman, E., Soukiazian, S., Verbrugge, M., and Finamore, P., 2011. "Cycle-life model for graphiteLiFePO4 cells“. Journal of Power Sources, 196, 3942-3948.

https://doi.org/10.1016/j.jpowsour.2010.11.134

Wang, M.S., Song, W.L., and Fan L.Z., 2015. "Three-Dimensional Interconnected Network of Graphene-Wrapped Silicon/Carbon Nanofiber Hybrids for Binder-Free Anodes in Lithium-Ion Batteries". ChemElectroChem, 2, 1699-1706.

https://doi.org/10.1002/celc.201500187 
Wang, T., Tseng, K., and Zhao, J., 2015. "Development of efficient aircooling strategies for lithium-ion battery module based on empirical heat source model". Applied Thermal Engineering, 90, 521-529. https://doi.org/10.1016/j.applthermaleng.2015.07.033

Wiedemann, A. H., Goldin, G. M., Barnett, S. A., Zhu, H., and Kee, R. J., 2013. "Effects of three-dimensional cathode microstructure on the performance of lithium-ion battery cathodes". Electrochimica Acta, 88, $580-588$

https://doi.org/10.1016/j.electacta.2012.10.104

Wikner, E., and Thiringer, T., 2018. "Extending Battery Lifetime by Avoiding High SOC”. Applied Sciences, 8(10), 1825. https://doi.org/10.3390/app8101825

Wright, R., Christophersen, J., Motloch, C., Belt, J., Ho, C., Battaglia, V., and Sutula, R., 2003. "Power fade and capacity fade resulting from cycle-life testing of Advanced Technology Development Program lithium-ion batteries". Journal of Power Sources, 119-121, 865-869. https://doi.org/10.1016/s0378-7753(03)00190-3

Wu, F., Maier, J., and Yu, Y., 2020. "Guidelines and trends for nextgeneration rechargeable lithium and lithium-ion batteries". Chemical Society Reviews, 49(5), 1569 - 1614. https://doi.org/10.1039/C7CS00863E

Wu, T., Chen, H., Wang, Q., and Sun, J., 2018. "Comparison analysis on the thermal runaway of lithium-ion battery under two heating modes". Journal of Hazardous Materials, 344, 733-741. https://doi.org/10.1016/j.jhazmat.2017.11.022

Wu, W., Qiu, X., Wang, S., 2018. "Low-temperature reversible capacity loss and aging mechanism in lithium-ion batteries for different discharge profiles". International Journal of Energy Research, 43, 243253.

https://doi.org/10.1002/er.4257

Wu, Y., Keil, P., Schuster, S. F., and Jossen, A., 2017. "Impact of Temperature and Discharge Rate on the Aging of a LiCoO2/LiNi0.8Co0.15A10.05O2Lithium-Ion Pouch Cell". Journal of The Electrochemical Society, 164 (7), A1438-A1445. https://doi.org/10.1149/2.0401707jes

Wu, Z., Wang, Z., Qian, C., Sun, B., Ren, Y., Feng, Q., and Yang, D., 2019. "Online prognostication of remaining useful life for random discharge lithium-ion batteries using a gamma process model". 2019 20th International Conference on Thermal, Mechanical and MultiPhysics Simulation and Experiments in Microelectronics and Microsystems (EuroSimE).

https://doi.org/10.1109/eurosime.2019.8724567
Xia, Q., Wang, Z., Ren, Y., Tao, L., Lu, C., Tian, J., Hu, D., Wang, Y., Su, Y., Chong, J., Jin, H., and Lin, Y., 2019. "A modified reliability model for lithium-ion battery packs based on the stochastic capacity degradation and dynamic response impedance," Journal of Power Sources, 423, 40-51. https://doi.org/10.1016/j.jpowsour.2019.03.042

Yan, B., Lim, C., Yin, L., and Zhu, L., 2013. "Simulation of heat generation in a reconstructed $\mathrm{LiCoO}_{2}$ cathode during galvanostatic discharge". Electrochimica Acta, 100, 171-179. https://doi.org/10.1016/j.electacta.2013.03.132

Yan, J., Li, K., Chen, H., Wang, Q., and Sun, J., 2016. "Experimental study on the application of phase change material in the dynamic cycling of battery pack system". Energy Conversion and Management, 128, $12-19$. https://doi.org/10.1016/j.enconman.2016.09.058

Yang, X.-G., Leng, Y., Zhang, G., Ge, S., and Wang, C.-Y., 2017. "Modeling of lithium plating induced aging of lithium-ion batteries: Transition from linear to nonlinear aging". Journal of Power Sources, 360, 28-40.

https://doi.org/10.1016/j.jpowsour.2017.05.110

Yang, Z., Patil, D., and Fahimi, B., 2018. "Online Estimation of Capacity Fade and Power Fade of Lithium-Ion Batteries Based on Input-Output Response Technique". IEEE Transactions on Transportation Electrification, 4(1), 147-156. https://doi.org/10.1109/tte.2017.2775801

Yuksel, T., Litster, S., Viswanathan, V., and Michalek, J.J., 2017. "Plug-in hybrid electric vehicle $\mathrm{LiFePO}_{4}$ battery life implications of thermal management, driving conditions, and regional climate". Journal of Power Sources, 338, 49-64. https://doi.org/10.1016/j.jpowsour.2016.10.104

Zhao, R., Gu, J., and Liu, J., 2015. “An experimental study of heat pipe thermal management system with wet cooling method for lithium ion batteries". Journal of Power Sources, 273, 1089-1097. https://doi.org/10.1016/j.jpowsour.2014.10.007

Zheng, S., Wang, L., Feng, X., He, X., 2018. "Probing the heat sources during thermal runaway process by thermal analysis of different battery chemistries". Journal of Power Sources, 378, 527-536.

https://doi.org/10.1016/j.jpowsour.2017.12.050 